\title{
REVISÃO SISTÊMICA DA LITERATURA INTERNACIONAL SOBRE AVALIAÇÃO DE DESEMPENHO NA GESTÃO DE P\&D
}

\section{INTERNATIONAL LITERATURE SYSTEMIC REVIEW ON R\&D MANAGEMENT PERFORMANCE EVALUATION}

\author{
Alysson Diego Marafon ${ }^{1}$; Leonardo Ensslin ${ }^{2}$; Sandra Rolim Ensslin ${ }^{3}$; Rogério Tadeu \\ Lacerda $^{4}$ \\ ${ }^{1}$ Universidade Federal de Santa Catarina - UFSC - Florianópolis - Brasil \\ alyssonmarafon@gmail.com \\ ${ }^{2}$ Universidade Federal de Santa Catarina - UFSC - Florianópolis - Brasil \\ leonardoensslin@gmail.com \\ ${ }^{3}$ Universidade Federal de Santa Catarina - UFSC - Florianópolis - Brasil \\ sensslin@gmail.com \\ ${ }^{4}$ Universidade Federal de Santa Catarina - UFSC - Florianópolis - Brasil \\ rogerlacerda@gmail.com
}

\begin{abstract}
Resumo
$O$ presente trabalho tem como objetivo, com base em um conhecimento inicial do pesquisador sobre gestão de Pesquisa e Desenvolvimento (P\&D), expandi-lo em níveis que lhe permitam formar um Portfólio Bibliográfico $(P B)$ sobre o tema; explicitar características desse PB em temos dos mais destacados artigos, autores e periódicos; proceder à análise crítica desse PB a partir da afiliação teórica estabelecida; e identificar lacunas passíveis de se tornarem futuras pesquisas na área. Para isso, realiza-se uma revisão sistêmica da literatura internacional por meio de um processo estruturado, informado pelo instrumento Knowledge Development Process - Construtivist (Proknow-C), composto por quatro etapas: i) seleção de um Portfólio de artigos destacados sobre o tema da pesquisa; ii) análise bibliométrica do Portfólio; iii) análise sistêmica; e iv) definição da pergunta de pesquisa e objetivo de futuras pesquisas. A importância desta pesquisa se alicerça no arcabouço deixado às futuras pesquisas sobre P\&D e também na legitimação do processo de revisão sistêmica como um gerador de conhecimento no pesquisador.
\end{abstract}

Palavras-chave: avaliação de desempenho; gestão de P\&D; revisão sistêmica.

\section{Introdução}

Até o final do segundo milênio, pouca atenção era direcionada à área de Pesquisa e Desenvolvimento (P\&D). Mesmo as empresas que disputavam seus mercados à base de tecnologia consideravam o setor isoladamente alocando uma quantidade de recursos quando 
se esperava que inovações fossem desenvolvidas (OJANEN, VUOLA, 2006). Essas inovações podem ser traduzidas como resultados do processo de exploração de uma ideia que agrega valor ao mercado e que traz retorno comercial (OECD, EUROSTAT, 2005; ADAMS, BESSANT, PHELPS, 2006). Então, assumindo que a inovação começa sempre com uma ideia (CHURCILL, PETER, 2000), e sendo essa definida como a reprodução mental de um objeto não realmente presente para os sentidos (BALDWIN, 2011), instalava-se a dificuldade em gerir o processo de pesquisa e desenvolvimento (DONNELLY, 2000).

Todavia atualmente as empresas têm se preocupado mais com a utilização dos recursos alocados em $\mathrm{P} \& \mathrm{D}$, pois os investimentos no setor são cada vez maiores e tais questões estão presentes nas decisões estratégicas das organizações (WANG, CHIN, TZENG, 2010). Organizações públicas e privadas de economias emergentes como China e Brasil investem em P\&D 1.42\% (MOST, 2010) e 1.1\% (MCT, 2010), respectivamente, do seu PIB (Produto Interno Bruto). Países ricos, em média, possuem esse índice em 2,2\% (OECD, 2008). Isso significa que, considerando o PIB do mundo de 62 trilhões de dólares em 2010, as economias da União Europeia, dos EUA, da China, do Japão, da Alemanha, da França, do Reino Unido, da Itália, do Brasil e do Canadá investiram mais que um trilhão de dólares em Pesquisa e Desenvolvimento no ano (INTERNATIONAL MONETARY FUND, 2011).

Os benefícios trazidos pelo $\mathrm{P} \& \mathrm{D}$ são inquestionáveis devido ao impacto que causam no desempenho das organizações; ou seja, a intensidade do P\&D tem influência direta na sustentabilidade do negócio (BAUMOL, WOLFF, 1983; DOSI, 1988; MORBEY, REITHNER, 1990; ITO, PUCIK, 1993; LONG, RAVENSCRAFT, 1993; LEE, SHIN, 1995). Resultados tangíveis, como produtos e serviços, podem trazer taxas de retorno financeiro que variam desde 10 até mais de 100\% ao ano sobre o valor investido (EARTO, 2010; FASTS, 2010). Em aspectos intangíveis, emergem os ganhos de propriedade intelectual, que significam capital humano (competências humanas e conhecimento das pessoas), capital relacional (marca e relacionamento com clientes) e capital estrutural (cultura da organização, patentes e bases de informação) (VUOLLE, LÖNNQVIST, VAN DER MEER, 2009; ENSSLIN et al, 2008; ENSSLIN, CARVALHO, 2007). Mas, sobretudo, há o efeito propagação que uma inovação oriunda do $\mathrm{P} \& \mathrm{D}$ pode ter por toda a cadeia produtiva, aumentando a geração de empregos, arrecadação de impostos, atração de investimentos, dentre outros que refletem geração de riquezas.

Dessa forma, as organizações passam a focar o processo de P\&D na busca pelo aumento da competitividade, demandando-a por uma estrutura de gestão complexa (GARCÍA-VALDERRAMA, MULERO-MENDIGORRI, REVUELTA-BORDOY, 2008). 
Reconhece-se, então, como fator crítico de sucesso que o gerenciamento do processo de P\&D seja feito por meio de técnicas e procedimentos modernos de gestão de negócios e de Avaliação de Desempenho. Avaliação de Desempenho é um conceito de gestão utilizado para construir, fixar e disseminar conhecimentos "por meio de atividades que identificam, organizam, mensuram ordinal e cardinalmente, integram e permitem visualizar o impacto das ações e seu gerenciamento" (AZEVEDO et al, 2011. p. 88); constituindo-se assim como a base para a tomada de decisão sobre qualquer situação que envolve escolha (ENSSLIN, MONTIBELLER, NORONHA, 2001; ENSSLIN et al, 2008; GIFFHORN et al, 2009; AZEVEDO et al, 2011).

Nesses termos, emergem problemas relacionados com a área de $\mathrm{P} \& \mathrm{D}$ sob a perspectiva de seu desempenho, que busca responder a estas perguntas: Onde estão os métodos, conceitos e estudos de aplicações de Avaliação de Desempenho relacionados ao processo de gestão de $\mathrm{P} \& \mathrm{D}$ mais relevantes da literatura? Quais são os artigos, autores e periódicos na área que mais se destacam no ambiente científico? Quais são os pontos fortes e pontos fracos do atual conhecimento sobre Avaliação de Desempenho no processo de gestão de $P \& D ?$

Ao responder essas perguntas, este trabalho tem como objetivo, por meio da construção do conhecimento no pesquisador, identificar lacunas passíveis de se tornarem futuras pesquisas que venham a contribuir em termos científicos e práticos para o processo de gestão de Pesquisa e Desenvolvimento (P\&D) sob o ponto de vista da avaliação de seu desempenho, com base na revisão da literatura internacional.

Acredita-se que reunir em um único material informações -(i) de um processo para identificar e selecionar artigos relevantes sobre Avaliação de Desempenho do processo de gestão de P\&D; (ii) de uma análise bibliométrica das publicações internacionais relevantes deste tema; (iii) de uma análise crítica dos artigos do Portfolio Bibliográfico com base na afiliação teórica adotada de Avaliação de Desempenho - será útil para que pesquisadores e profissionais da área direcionem seus esforços àquelas pesquisas que vão gerar contribuições científicas e práticas, baseadas no conhecimento gerado nesta pesquisa informado pelo processo e reflexões apresentadas.

Este artigo está estruturado da seguinte maneira: partindo da introdução aqui apresentada, a seção 2 apresenta a metodologia da pesquisa utilizada neste trabalho, englobando seu enquadramento metodológico e o instrumento de intervenção utilizado para orientar o desenvolvimento da pesquisa; a seção 3 é destinada à apresentação e discussão dos resultados, iniciando pela apresentação do PB, seguindo pela apresentação da bibliometria - 
dos artigos do $\mathrm{PB}$, das referências presentes nos artigos do PB e da análise bibliométrica combinada; na quarta seção, são apresentadas as conclusões e considerações finais, e, finalmente, apresentam-se as referências bibliográficas desta pesquisa.

\section{Metodologia da Pesquisa}

Esta seção tem como objetivo apresentar o enquadramento metodológico adotado neste trabalho, bem como o instrumento de intervenção utilizado em sua condução.

\subsection{Enquadramento metodológico}

Neste trabalho, será utilizada a classificação de pesquisa proposta por Tasca et al (2010), já adotada por Ensslin, Ensslin e Pacheco (2012), representada esquematicamente na Figura 1.

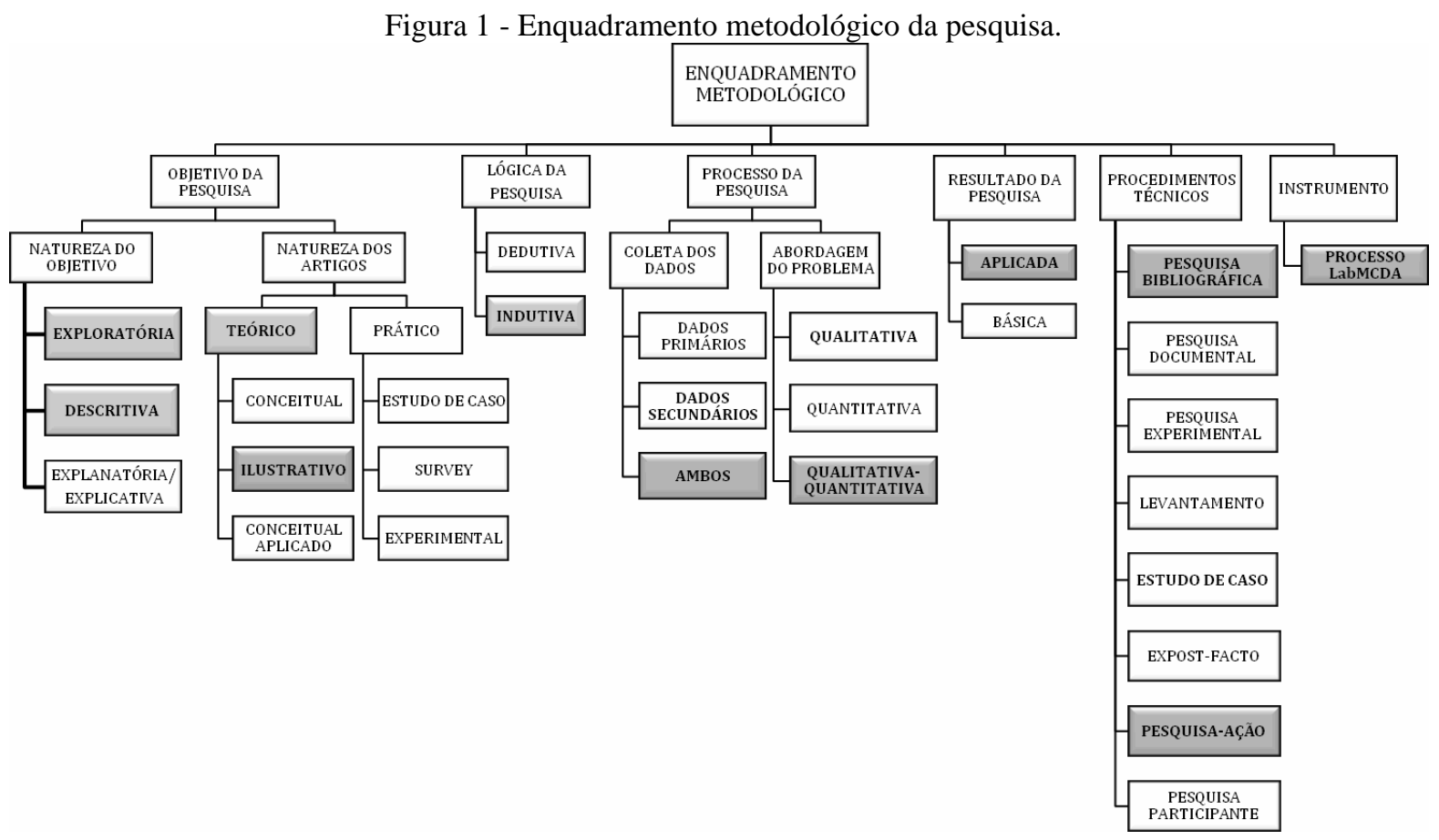

Fonte: Adaptado de Ensslin, Ensslin (2009), Tasca et al (2010) e Ensslin, Ensslin, Pacheco (2012)

\subsection{Instrumento de Intervenção: Knowledge Development Process - Construtivist (Proknow-C)}

O instrumento de intervenção utilizado para conduzir o processo de seleção de um Portfólio Bibliográfico de artigos destacados sobre o tema da pesquisa, de análise bibliométrica do Portfólio, de análise sistêmica e de definição de possíveis perguntas de pesquisa e objetivos é o Knowledge Development Process - Construtivist (ProKnow-C), 
conforme Figura 2. Sendo assim, o ProKnow-C, por meio de um processo estruturado e por sua abordagem construtivista, é capaz de gerar no pesquisador o conhecimento necessário para, na sequência, orientá-lo em investigações do tema em foco que ofereçam contribuições científicas à comunidade. Adicionalmente, a explicitação das características das publicações, a análise crítica dessas publicações e as possíveis indagações que podem ser investigadas constituem-se como contribuições científicas à academia científica (ENSSLIN, ENSSLIN, 2007; BORTOLUZZI et al, 2011; LACERDA et al, 2012).

O ProKnow-C foi criado pelos pesquisadores do LabMCDA (Laboratório de Metodologias Multicritério em Apoio à Decisão da Universidade Federal de Santa Catarina) (ENSSLIN, ENSSLIN, 2007) diante da constatação da ausência de uma abordagem que orientasse o pesquisador na seleção de artigos relevantes e alinhados ao assunto de investigação sob o ponto de vista da Avaliação de Desempenho, frente à diversidade de materiais disponíveis. Nos anos de 2005 e 2006, os pesquisadores do LabMCDA devotaram esforços na concepção dessa ideia; em 2007, a primeira versão do Proknow-C, ainda sem essa denominação, foi apresentada e operacionalizada aos alunos de Pós-Graduação da Engenharia de Produção da UFSC; em 2008, as primeiras pesquisas conduzidas por essa abordagem começam a ser submetidas à publicação e, a partir dos feedbacks dos avaliadores e do processo evolutivo gerado nas discussões do grupo LabMCDA, aperfeiçoamentos no processo estruturado foram realizados de tal forma que, em 2010, as primeiras publicações com esse instrumento, agora denominado de Prokwon-C, ocorressem.

Atualmente, o ProKnow-C encontra-se na versão 12, sendo utilizado para coleta e análise de artigos dos mais diversos temas associados à Avaliação de Desempenho (AD), tais como nas pesquisas de Afonso et al (2011), Bortoluzzi et al (2011), Lacerda, Ensslin, Ensslin (2011 e 2012), Rosa et al (2012); Ensslin, Ensslin, Pacheco (2012). 
Figura 2 - Etapas do Proknow-C

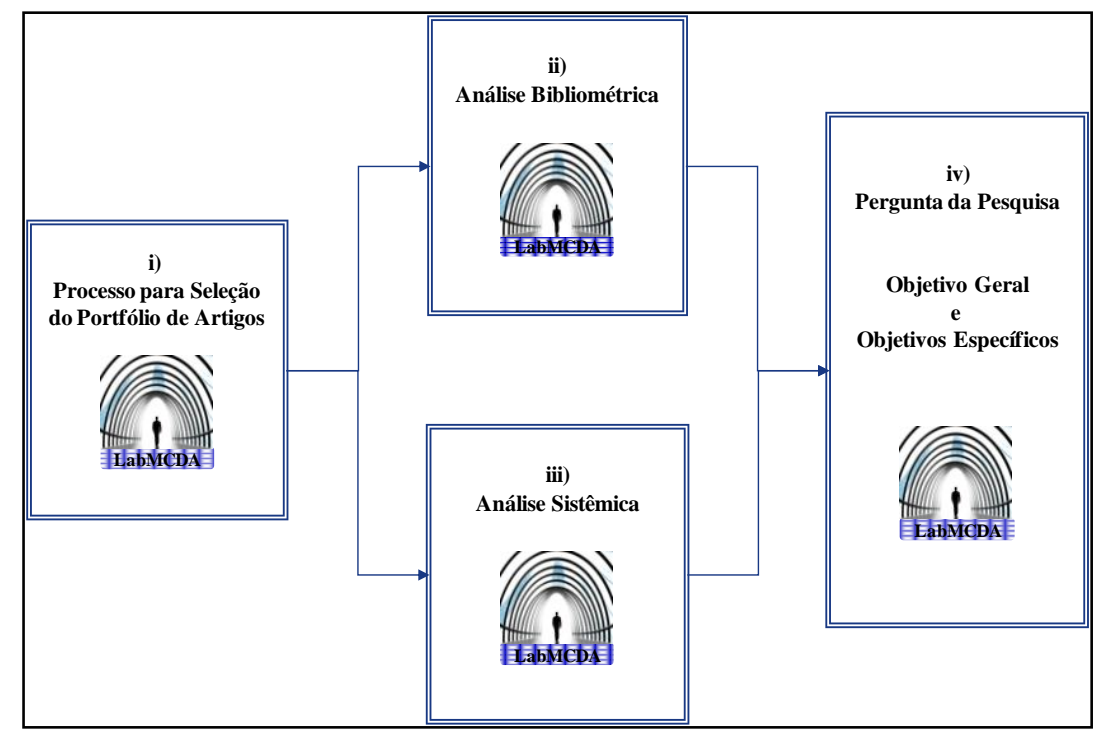

Fonte: Ensslin, Ensslin (2010)

O processo de seleção do Portfólio de artigos tem como objetivo identificar/resgatar um conjunto de artigos, nesta pesquisa, voltados à gestão de $\mathrm{P} \& \mathrm{D}$ sob o ponto de vista da Avaliação de Desempenho. O processo ocorre por meio de etapas estruturadas: busca dos artigos nas bases de dados, alinhamento dos trabalhos com o tema de pesquisa e seleção pela relevância acadêmica dos artigos.

A análise bibliométrica é cada vez mais empregada para medir a produção científica e, ao aplicá-la na investigação de determinado campo do conhecimento, torna-se possível apresentar informações dessas publicações quantificando-as por meio de análises estatísticas (SAES, 2000). No Proknow-C, a análise bibliométrica é realizada tanto no Portfólio Bibliográfico selecionado quanto nas referências desse Portfólio a fim de se conhecerem as características das publicações dessa área de conhecimento em termos do número de citações, dos autores mais prolíficos e dos periódicos mais devotados ao tema.

A terceira etapa é a análise sistêmica, a qual é um processo científico que tem como objetivo realizar a análise de conteúdo dos artigos selecionados. Essa análise utiliza uma estrutura baseada em seis lentes derivadas do conceito de Avaliação de Desempenho adotado para a pesquisa pelos autores do trabalho (LACERDA, ENSSLIN, ENSSLIN, 2011).

Por último, como conclusão das etapas anteriores, como conhecimento gerado, emergem possíveis perguntas de pesquisas, advindas das lacunas encontradas nas publicações selecionadas sobre o processo de gestão de Pesquisa e Desenvolvimento (P\&D) na perspectiva da Avaliação de Desempenho. 


\section{Apresentação e discussão dos resultados: seleção, análise bibliométrica e sistêmica do}

PB

\subsection{Seleção do PB}

A seleção dos artigos que compõem o Portfólio final acontece conforme as etapas mostradas na Figura 3.

No Portal de Periódico da CAPES, escolheram-se as bases de dados SCOPUS, EBSCO, WILSON WEB, ISI e ENGINEERING VILLAGE para elaboração do trabalho. Os autores desta pesquisa entendem que tais bases contêm uma representatividade adequada para a abordagem a ser aplicada.

Figura 3 - Processo para seleção do Portfólio de artigos

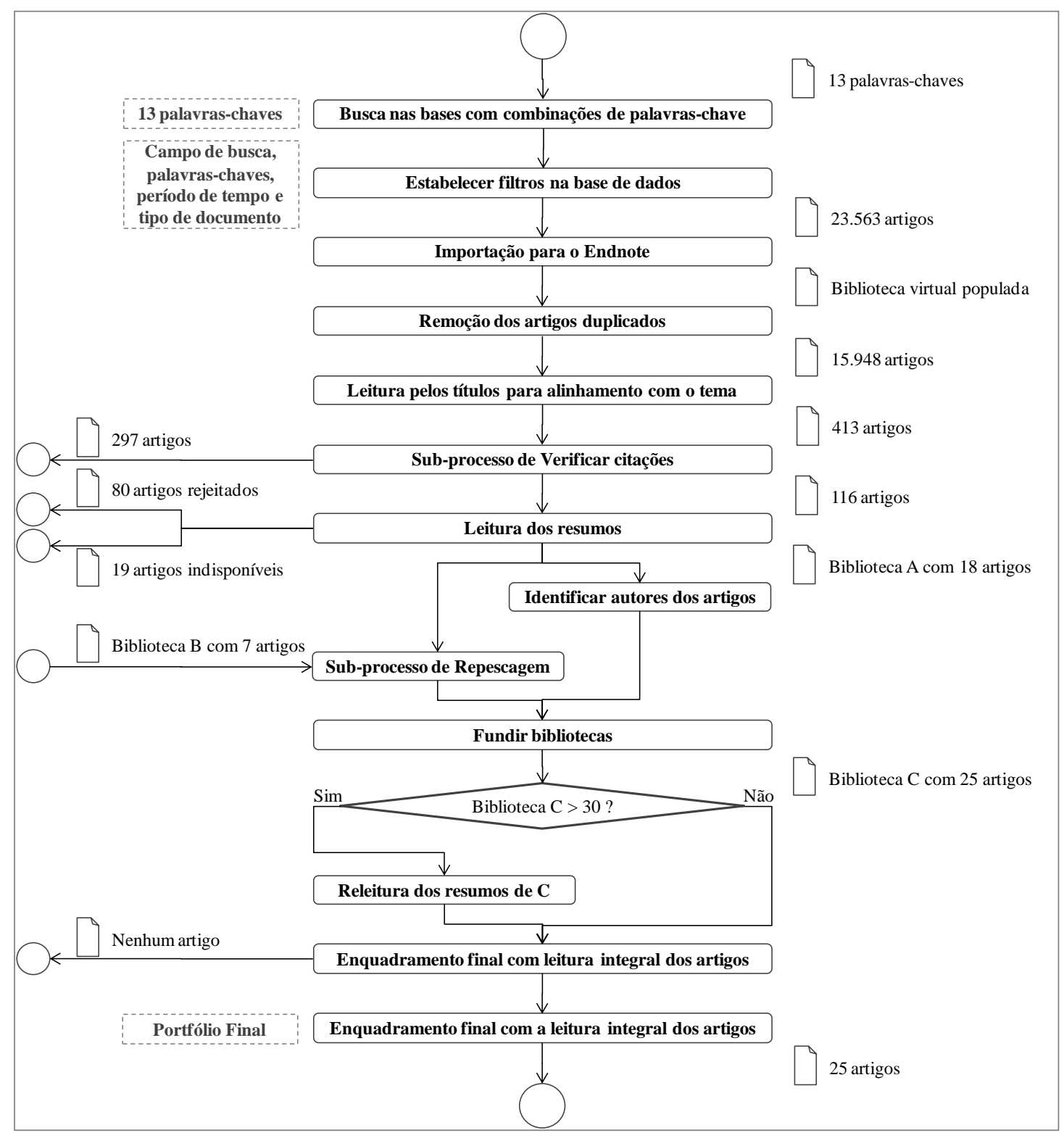

Fonte: Adaptado de Lacerda, Ensslin, Ensslin (2012) 
A partir destas 13 palavras/expressões - R\&D, Product Lifecycle, Product Developoment, New Prodcut, Project, Innovation, Management, Productivity, Measurement, Performance, Evaluation, Appraisal e Assessment - e suas combinações foram feitas 133 buscas nas bases com delimitação temporal, filtrando os artigos publicados a partir de 2001 . A busca foi feita nos campos título (article title), resumo (abstracts) e palavra-chave (keywords).

O resultado das buscas forneceu 23.563 artigos que, por meio da ferramenta EndNote, foram exportados das bases de dados para povoar uma biblioteca virtual. Com essa ferramenta foi identificada a necessidade de remover 7.615 artigos duplicados, reduzindo o número de artigos para 15.948.

A etapa seguinte consistiu na leitura dos títulos dos artigos. Para estar alinhado, considerou-se que um artigo deveria conter pelo menos um dos seguintes assuntos: i) Método ou uma abordagem de $\mathrm{AD}$ do processo de $\mathrm{P} \& \mathrm{D}$; ii) explicação ou conceituação de $\mathrm{AD}$ no processo de P\&D; e, iii) um estudo de caso ou aplicação. Como resultado, chegou-se a um número de 413 artigos selecionados. Em seguida, utilizou-se do Google Scholar (2011) e foi feita a análise de citações dos artigos e a seleção dos artigos mais citados. Foram selecionados 116 artigos que correspondiam a 80\% das citações existentes nos 413 artigos.

Considerando, então, os mesmos três assuntos para o alinhamento dos títulos, fez-se a leitura dos resumos e o número de artigos foi reduzido para 18 artigos, sendo que 80 foram rejeitados pelo desalinhamento com o tema de pesquisa e 19 não estarem disponíveis gratuitamente.

O processo de seleção de artigos, devido ao filtro pela quantidade de citações, pode excluir artigos importantes na área de autores destacados, publicados recentemente e, por esse motivo, não contém número considerável de citações. Então, por meio da repescagem, revisitaram-se artigos publicados em 2008, 2009 e 2010, alinhados ao tema de pesquisa, e 7 artigos foram agregados ao Portfólio a partir do resumo. Ao incorporar os artigos recuperados na análise de repescagem, obteve-se um total de 25 artigos, listados na Figura 4. 


\section{Referências dos artigos do portfólio final}

ADAMS, R.; BESSANT, J.; PHELPS, R. Innovation management measurement: A review. International Journal of Management Reviews, v. 8, n. 1, p. 21-47, 2006.

BREMSER, W. G.; BARSKY, N. P. Utilizing the balanced scorecard for R\&D performance measurement. R\&D Management, v. 34, n. 3, p. 229-238, 2004.

CALANTONE, R. J.; CHAN, K.; CUI, A. S. Decomposing product innovativeness and its effects on new product success. Journal of Product Innovation Management, v. 23, n. Compendex, p. 408-421, 2006.

CEDERGREN, S.; WALL, A.; NORSTRM, C. Evaluation of performance in a product development context. Business Horizons, v. 53, n. 4, p. 359-69, 2010.

CHEN, M.-Y.; HUANG, M.-J.; CHENG, Y.-C. Measuring knowledge management performance using a competitive perspective: An empirical study. Expert Systems with Applications, v. 36, n. p. 8449-8459, 2009.

CHIESA, V. et al. Performance measurement in R\&D: exploring the interplay between measurement objectives, dimensions of performance and contextual factors. R\&D Management, v. 39, n. 5, p. 488-518, 2009.

COOPER, R.; EDGETT, S.; KLEINSCHMIDT, E. Portfolio management for new product development: Results of an industry practices study. R\&D Management, v. 31, n. 4, p. 361-380, 2001.

CORMICAN, K.; O'SULLIVAN, D. Auditing best practice for effective product innovation management. Technovation, v. 24, n. 10, p. 819-829, 2004.

EILAT, H.; GOLANY, B.; SHTUB, A. R\&D project evaluation: An integrated DEA and balanced scorecard approach. Omega-International Journal of Management Science, v. 36, n. 5, p. 895-912, 2008.

ELMQUIST, M.; LE MASSON, P. The value of a 'failed' R\&D project: an emerging evaluation framework for building innovative capabilities. R\&D Management, v. 39, n. 2, p. 136-152, 2009.

GARCÍA-VALDERRAMA, T.; MULERO-MENDIGORRI, E. Content validation of a measure of R\&D effectiveness. R\&D Management, v. 35, n. 3, p. 311-331, 2005.

GARCÍA-VALDERRAMA， T.; MULERO-MENDIGORRI， E.; REVUELTA-BORDOY， D. A balanced scorecard framework for R\&D. European Journal of Innovation Management, v. 11, n. 2, p. 241-281, 2008.

HAGEDOORN, J.; CLOODT, M. Measuring innovative performance: is there an advantage in using multiple indicators? Research Policy, v. 32, n. 8, p. 1365-1379, 2003.

HART, S. et al. Industrial companies' evaluation criteria in new product development gates. Journal of Product Innovation Management, v. 20, n. 1, p. 22-36, 2003.

LIN, B. W.; CHEN, J. S. Corporate technology portfolios and R\&D performance measures: A study of technology intensive firms. R\&D Management, v. 35, n. 2, p. 157-170, 2005.

MALLICK, D. N.; SCHROEDER, R. G. An integrated framework for measuring product development performance in high technology industries. Production and Operations Management, v. 14, n. 2, p. 142-158, 2005.

MIKKOLA, J. H. Portfolio management of R \& D projects: Implications for innovation management. Technovation, v. 21, n. 7, p. 423-435, 2001.

PANIZZOLO, R.; BIAZZO, S.; GARENGO, P. New product development assessment: Towards a normative-contingent audit. Benchmarking, v. 17, n. 2, p. 173-194, 2010.

PILLAI, A. S.; JOSHI, A.; RAO, K. S. Performance measurement of R and D projects in a multi-project, concurrent engineering environment. International Journal of Project Management, v. 20, n. 2, p. 165-177, 2002.

SANTIAGO, L. P.; BIFANO, T. G. Management of R\&D projects under uncertainty: A multidimensional approach to managerial flexibility. IEEE Transactions on Engineering Management, v. 52, n. 2, p. 269-280, 2005.

SCHMIDT, J. B.; SARANGEE, K. R.; MONTOYA, M. M. Exploring new product development project review practices. Journal of Product Innovation Management, v. 26, n. 5, p. 520-535, 2009.

VERMA, D.; SINHA, K. K. Toward a theory of project interdependencies in high tech R \& D environments. Journal of Operations Management, v. 20, n. 5, p. 451-468, 2002.

VON ZEDTWITZ, M.; GASSMANN, O.; BOUTELLIER, R. Organizing global R\&D: Challenges and dilemmas. Journal of International Management, v. 10, n. 1 SPEC ISS., p. 21-49, 2004.

VUOLLE, M.; LÖNNQVIST, A.; VAN DER MEER, J. Measuring the intangible aspects of an R\&D project. Measuring Business Excellence, v. 13, n. 2, p. 25-33, 2009.

WANG, J.; LIN, W.; HUANG, Y. H. A performance-oriented risk management framework for innovative R\&D projects. Technovation, v. 30, n. 11-12, p. 601-611, 2010.

Fonte: Autoria própria (2012) 


\subsection{Análise bibliométrica}

Entende-se por bibliometria um campo de estudos que aplica métodos estatísticos para analisar o curso da comunicação escrita de uma determinada disciplina, ou seja, a quantificação dos processos de comunicação escrita (PRITCHARD, 1969). Dentre as diversas possibilidades de aplicação do uso da bibliometria propostas (SPINAK, 1998), para o presente trabalho se destacam como principais: identificar artigos, autores e periódicos mais relevantes e produtivos; identificar tendências e crescimento do conhecimento; estudar dispersão e obsolescências dos campos científicos; adaptar políticas de aquisição; e descarte de publicações.

As próximas três subseções se referem aos resultados da bibliometria aplicada ao Portfólio selecionado de artigos, seguindo a sequência de análise mostrada na Figura 5.

Figura 5 - Fluxo do processo de análise bibliométrica

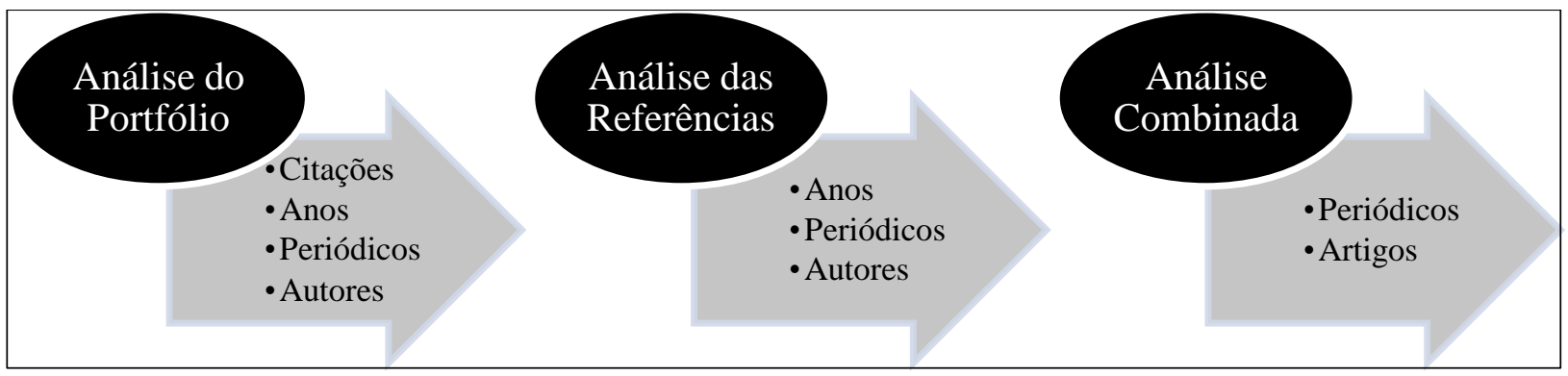

Fonte: Adaptado de Tasca et al (2010) ; Bortoluzzi et al (2011); Ensslin et al (2012); Lacerda et al, (2012); Rosa et al (2012).

\subsubsection{Análise bibliométrica do Portfólio}

A primeira análise do Portfólio selecionado busca identificar quais são os mais citados no meio acadêmico. Para isto utilizou-se o Google Acadêmico (2011) e os resultados são apresentados nas Figuras 6 e 7.

Figura 6 - Artigos do Portfólio mais citados na literatura

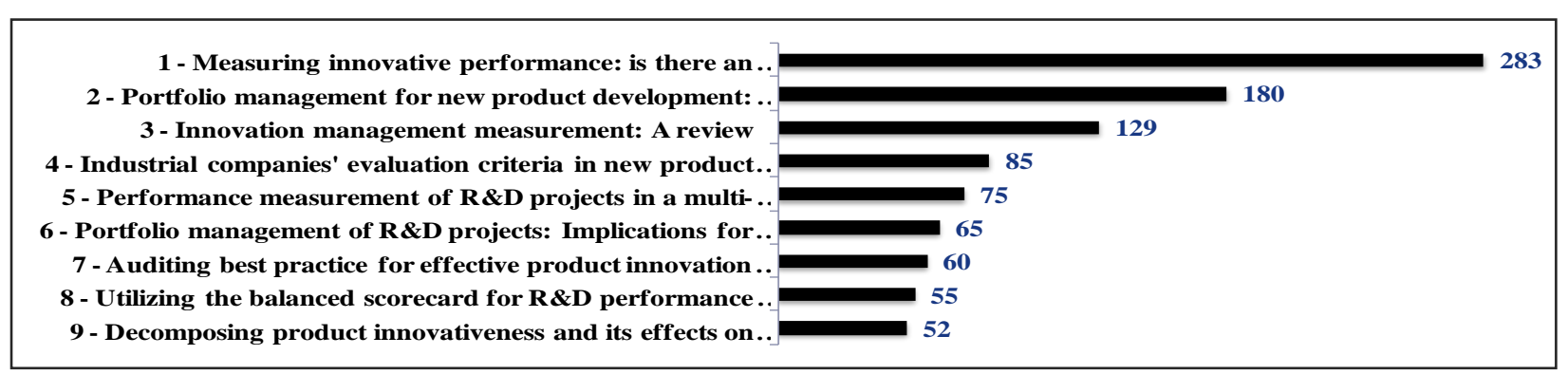

Fonte: Dados da pesquisa (2011)

Conforme é possível observar pela Figura 7, nove artigos selecionados representam 79\% das citações do Portfólio no meio acadêmico. 
Figura 7 - Número de citações acumuladas do artigo mais citado para o menos no Portfólio

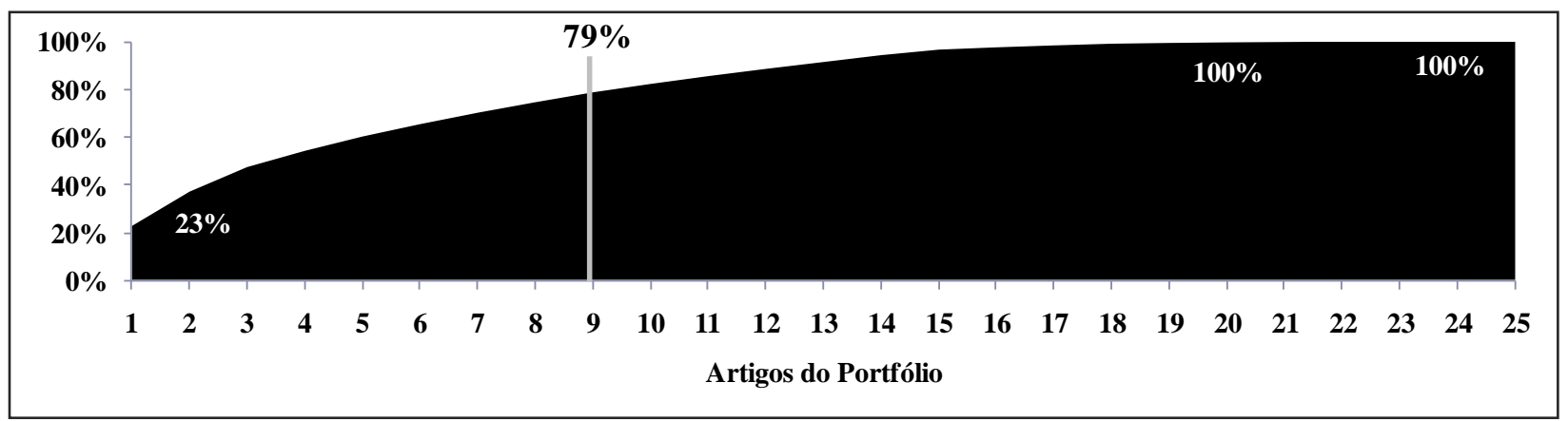

Fonte: Autoria própria (2011)

Tratando-se dos anos em que os artigos foram publicados, percebe-se que há homogeneidade das publicações, conforme a Figura 8, que mostra também 95\% das citações entre 2001 e 2007, referentes aos artigos mais citados selecionados, e 5\% das citações em publicações entre 2008 e 2010, associadas aos artigos selecionados pelo processo de repescagem.

Figura 8 - Artigos pela data de publicação

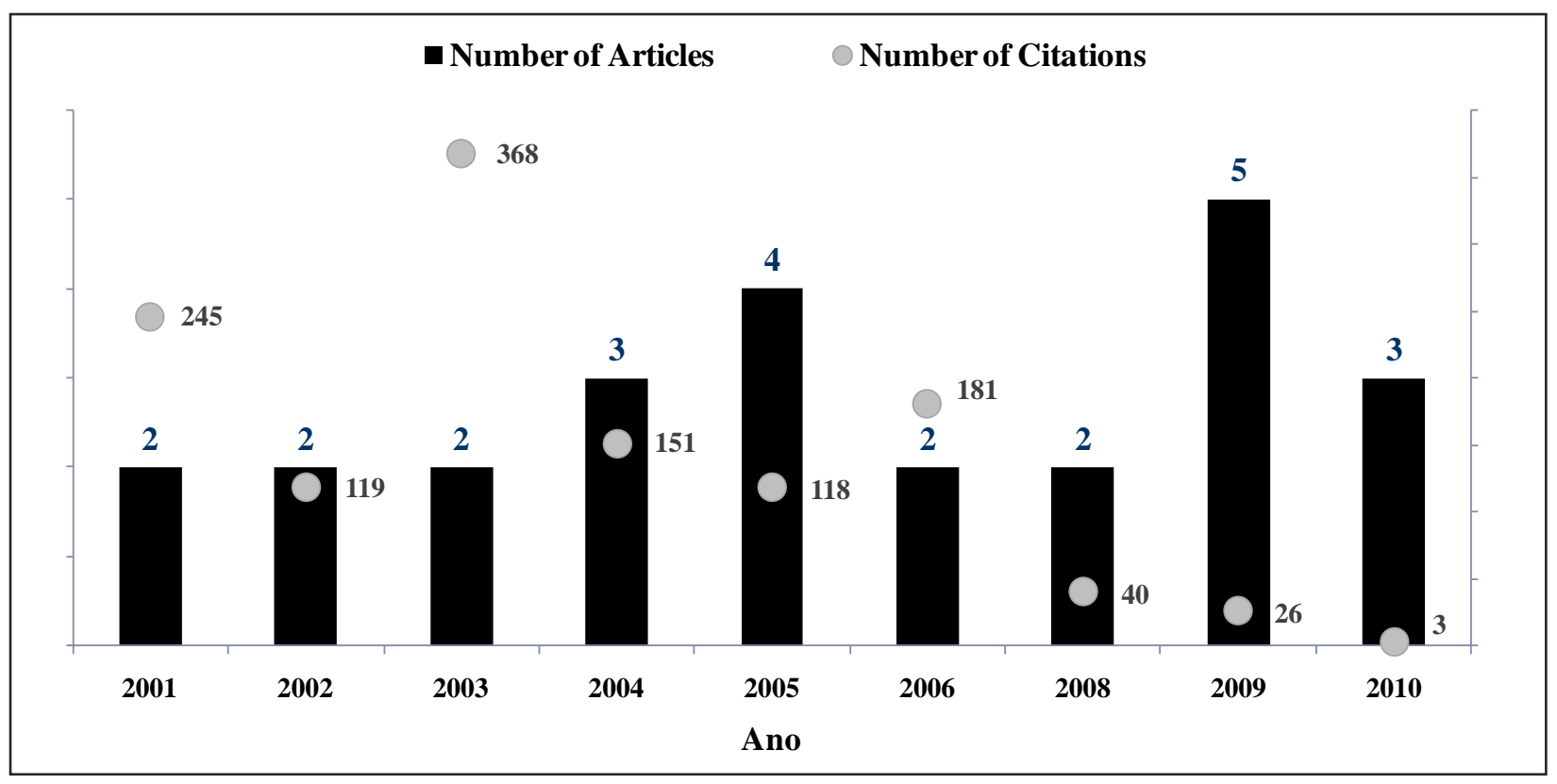

Fonte: Autoria própria (2011)

Por meio da terceira análise dos artigos do Portfólio, pode-se perceber que os 25 artigos estão publicados em 16 diferentes periódicos, dos quais $R \& D$ Management, Technovation e Journal of Product Innovation Management concentram 48\% dos trabalhos, conforme a Figura 9. 
Figura 9 - Artigos por periódicos

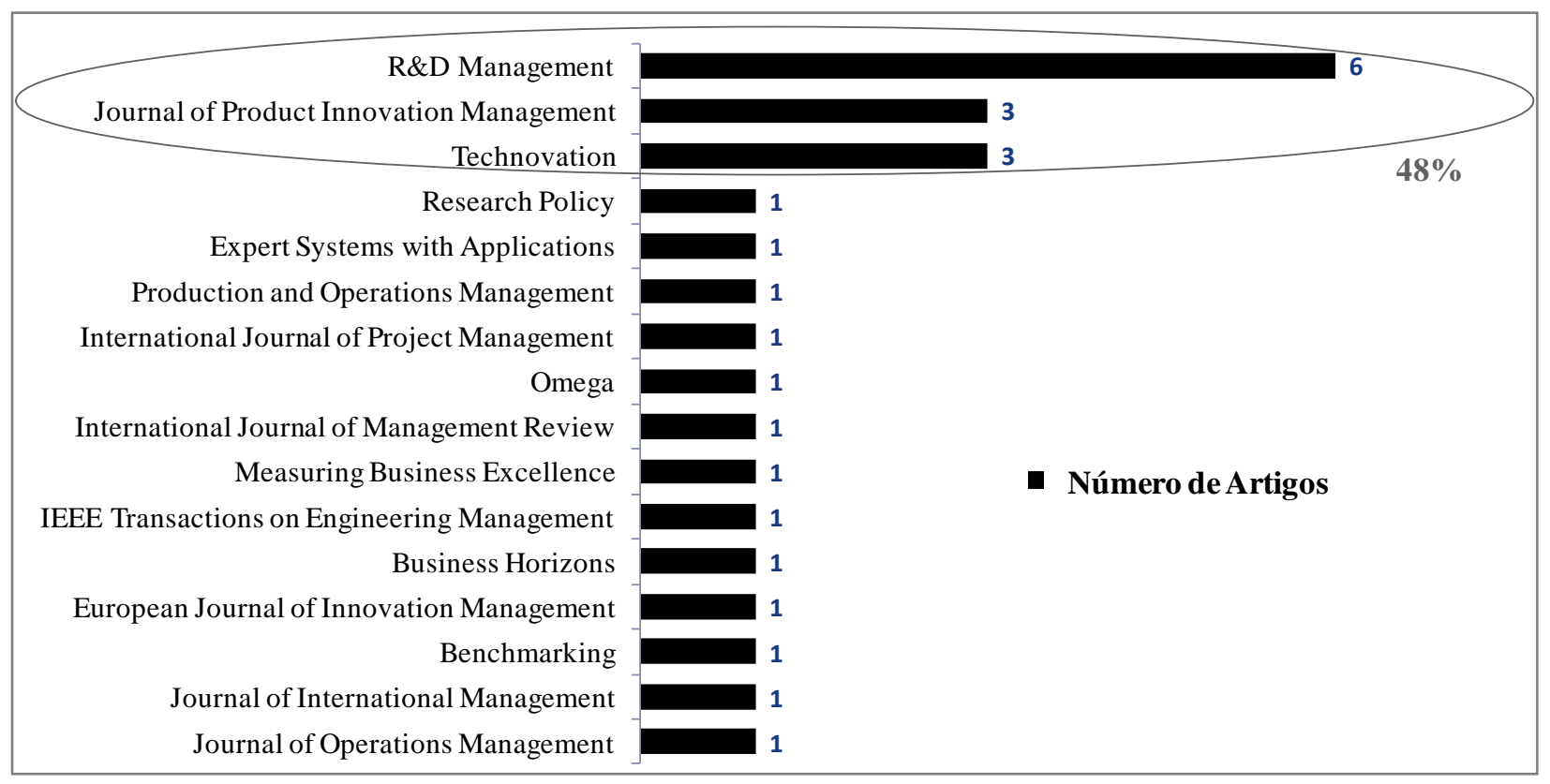

Fonte: Autoria própria (2011)

Por último, dos 64 autores envolvidos no Portfólio, o objetivo é identificar aqueles que mais publicaram, conforme mostrado na Figura 10.

Figura 10 - Autores dos artigos do Portfólio

\begin{tabular}{ll}
\hline & \\
\hline Mulero-Mendigorri, E. & 2 \\
\hline García-Valderrama, T. & 2 \\
\hline Kleinschmidt, E.J. & 1 \\
\hline Santiago, L.P. & 1 \\
\hline Mikkola, J.H. & 1 \\
\hline Biazzo, S. & 1 \\
\hline Verma, D. & 1 \\
\hline Bifano, T.G. & 1 \\
\hline Lin, W. & 1 \\
\hline Boutellier, R. & 1 \\
\hline O’Sullivan, D. & 1 \\
\hline Bremser, W.G. & 1 \\
\hline Shtub, A. & 1 \\
\hline Calantone, R.J. & 1 \\
\hline Wang, J. & 1 \\
\hline Cedergren, S. & 1 \\
\hline Le Masson, P. & 1 \\
\hline Chan, K. & 1 \\
\hline Mallick, D.N. & 1 \\
\hline Chen, M.Y. & 1 \\
\hline Barsky, N.P. & 1 \\
\hline Chen, S. & 1 \\
\hline
\end{tabular}

\begin{tabular}{ll}
\hline Phelps, R. & 1 \\
\hline Cheng, Y.C. & 1 \\
\hline Schmidt, J.B. & 1 \\
\hline Chiesa, V. & 1 \\
\hline Tzokas, N. & 1 \\
\hline Cloodt, M. & 1 \\
\hline Vuolle, M. & 1 \\
\hline Commandeur, H.R. & 1 \\
\hline Joshi, A. & 1 \\
\hline Cooper, R.G. & 1 \\
\hline Lazzarotti, V. & 1 \\
\hline Cormican, K. & 1 \\
\hline Lin, B.W. & 1 \\
\hline Cui, A.S. & 1 \\
\hline Lonnqvist, A. & 1 \\
\hline Edgett, S.J. & 1 \\
\hline Manzini, R. & 1 \\
\hline Eilat, H. & 1 \\
\hline Montoya-Weiss, M.M. & 1 \\
\hline Elmquist, M. & 1 \\
\hline Norstrom, C. & 1 \\
\hline
\end{tabular}

\begin{tabular}{ll}
\hline Frattini, F. & 1 \\
\hline Panizzolo, R. & 1 \\
\hline Pillai, A.S. & 1 \\
\hline Bessant, J. & 1 \\
\hline Rao, K.S. & 1 \\
\hline Revuelta-Bordoy, D. & 1 \\
\hline Garengo, P. & 1 \\
\hline Sarangee, K.R. & 1 \\
\hline Gassmann, O. & 1 \\
\hline Schroeder, R.G. & 1 \\
\hline Golany, B. & 1 \\
\hline Sinha, K.K. & 1 \\
\hline Hagedoorn, J. & 1 \\
\hline vander Meer, J. & 1 \\
\hline Hart, S. & 1 \\
\hline von Zedtwitz, M. & 1 \\
\hline Huang, M.J. & 1 \\
\hline Wall, A. & 1 \\
\hline Huang, Y.H. & 1 \\
\hline Adams, R. & 64 \\
\hline Hultink, E.J. & \\
\hline Total autores diferentes
\end{tabular}

Fonte: Autoria própria (2011) 
Os resultados obtidos demonstram dispersão dos autores, em que somente MULEROMENDIGORRI, GARCÍA-VALDERRAMA contribuem com dois artigos escritos. Todos os demais cooperam com apenas um artigo.

\subsubsection{Análise bibliométrica das referências dos artigos do Portfólio}

Quando se analisam as 1.368 referências bibliográficas dos artigos selecionados, observa-se $47 \%$ dessas publicadas entre 1995 e 2002, ao passo que se tem a publicação mais antiga e a mais recente nos anos de 1944 e 2010, respectivamente, conforme Figura 11.

Figura 11 - Referências dos artigos por ano de publicação

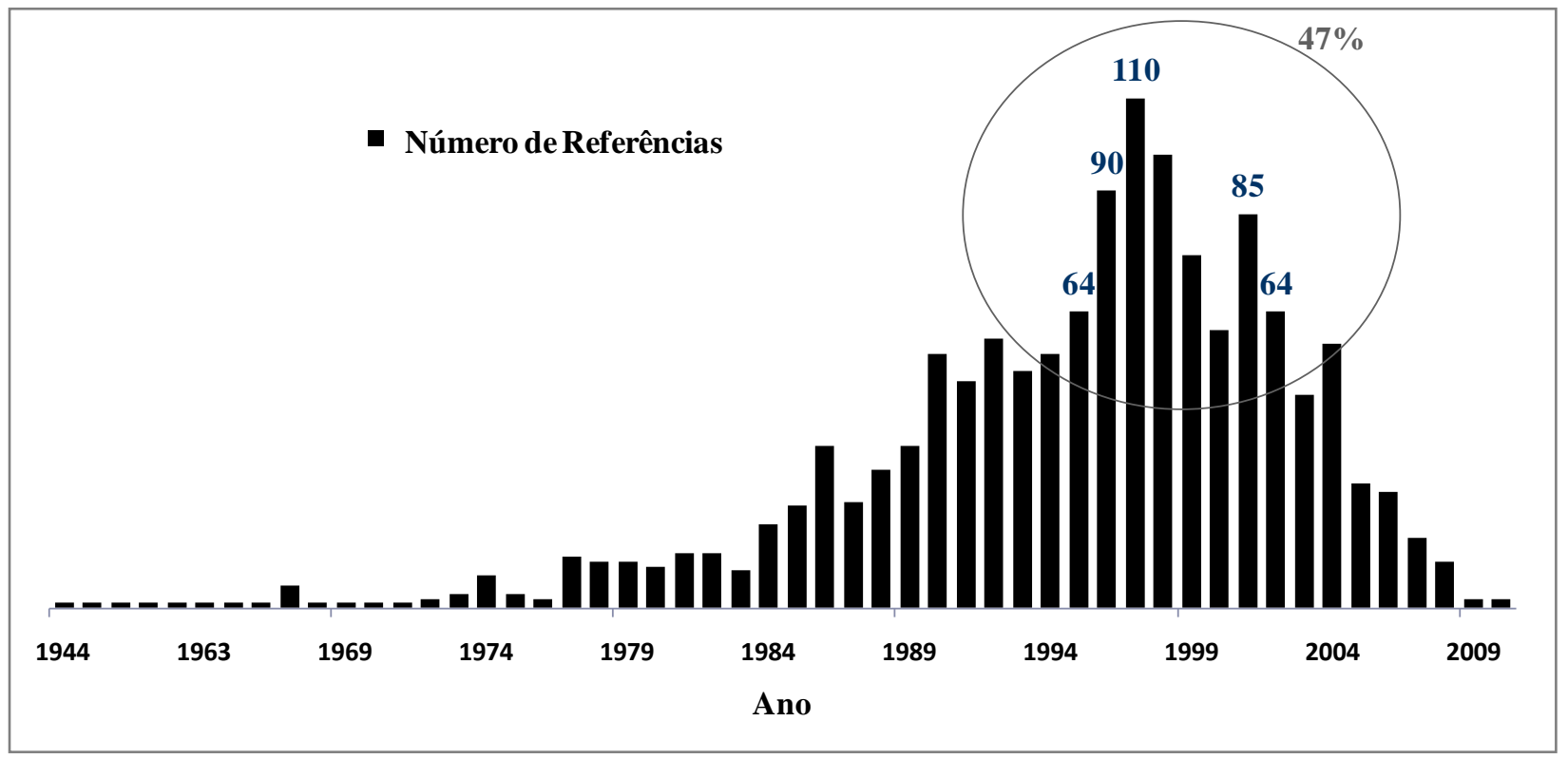

Fonte: Autoria própria (2011)

Ao se observarem os periódicos em que as referências bibliográficas estão publicadas, encontram-se 343 periódicos. Desse total, 22 periódicos contêm 52\% do total dos trabalhos apresentados na Figura 12. Aqueles que contêm maior número de artigos são: Journal of Product Innovation Management, Research Technology Management, R\&D Management, Research Policy, Harvard Business Review e IEEE Transactions on Engineering Management. 
Figura 12 - Referências dos artigos por periódico

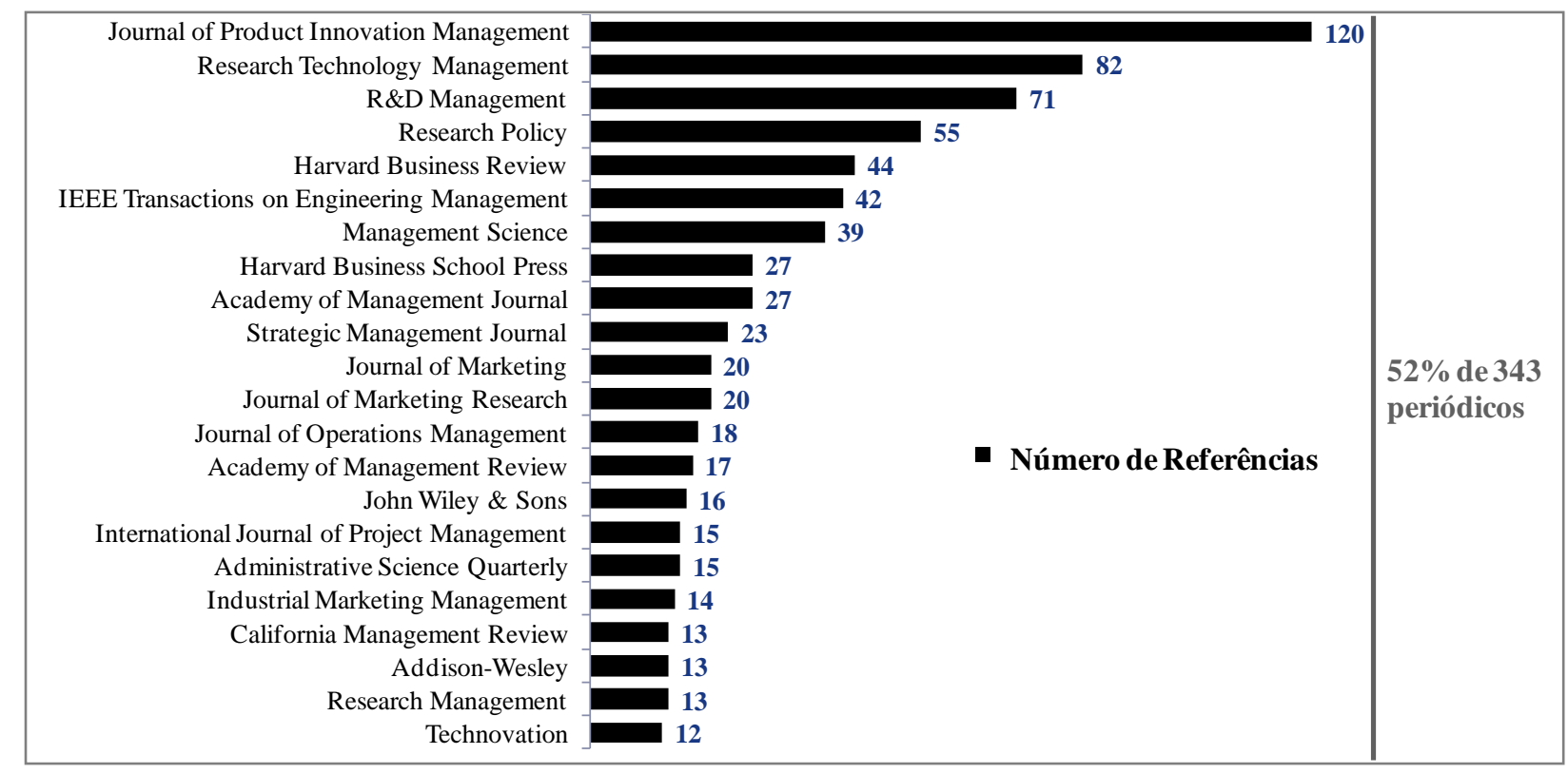

Fonte: Autoria própria (2011)

$\mathrm{Na}$ sequência, revelam-se os autores que mais são referenciados pelo Portfólio selecionado, conforme Figura 13.

Figura 13 - Número de referências por autor

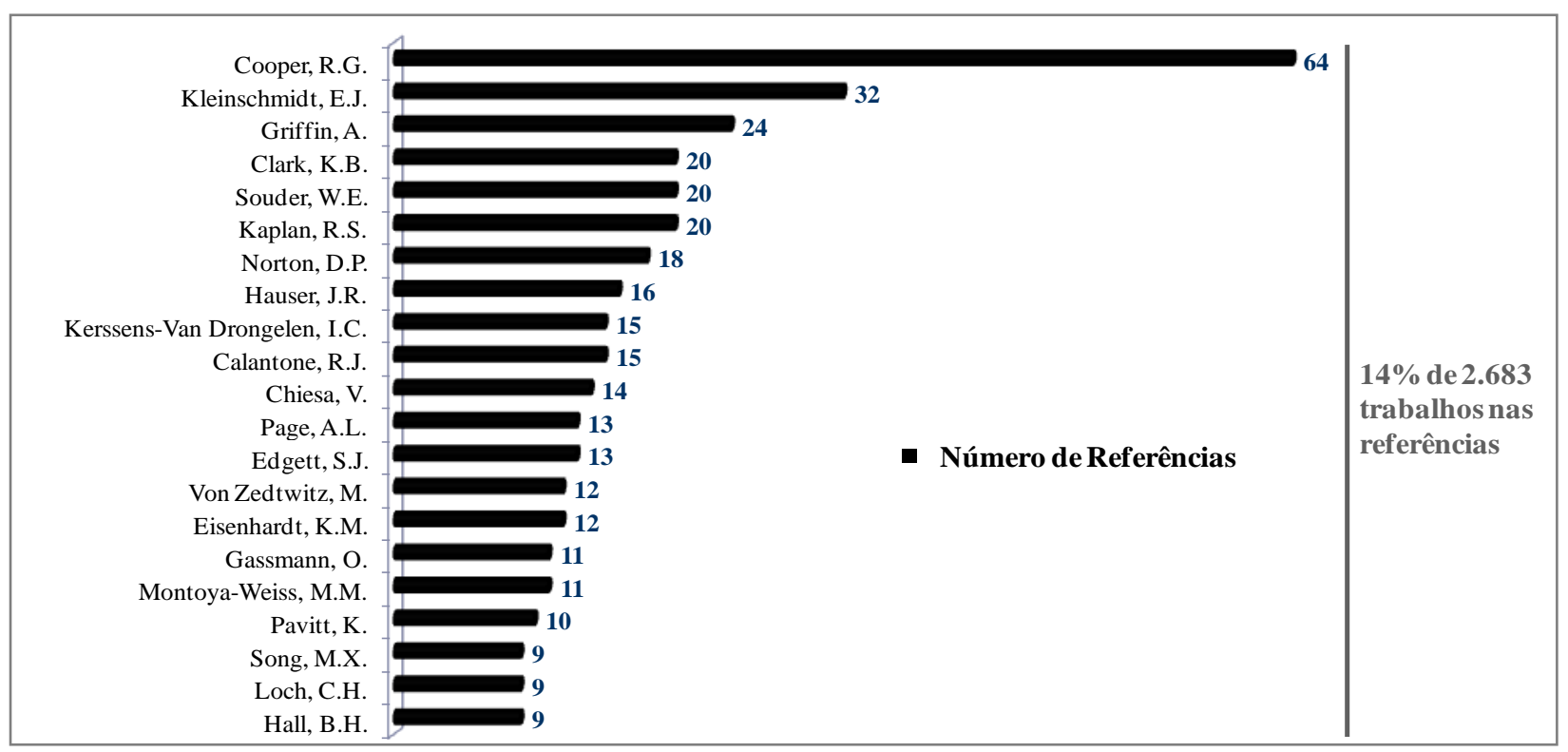

Fonte: Autoria própria (2011)

Foram encontrados 1.531 autores para 2.683 trabalhos nas referências, em que 21 dos autores cooperaram para a realização de $14 \%$ das publicações, como apresenta a Figura 9. Destes 21 autores, oito deles também contribuem com os artigos do Portfólio selecionado: 
COOPER, R. G.; KLEINSCHIMIDT, E. J.; CALANTONE, R. J.; CHIESA, V.; EDGETT, S. J.; VON ZEDTWITZ, M.; GASSMANN, O.; e MONTOYA-WEISS, M. M.

\subsubsection{Análise combinada}

$\mathrm{Na}$ terceira etapa do processo, a análise bibliométrica indica quais periódicos e artigos da amostra de 25 são os mais relevantes no meio acadêmico. Para isso, convencionam-se duas análises: i) Análise combinada dos periódicos onde estão publicados os artigos do Portfólio com os periódicos onde estão publicados todos os trabalhos presentes das referências bibliográficas; ii) Análise combinada entre o número de citações dos artigos do Portfólio, buscado no Google Acadêmico (2011), com o número de vezes que os autores desses artigos apareceram nas referências bibliográficas. Para ambas, revelam-se quem são aqueles que contribuem com $80 \%$ nas duas dimensões de cada análise.

A Figura 14 apresenta a primeira análise, onde se conclui que há quatro periódicos de destaque que contêm $80 \%$ dos artigos do Portfólio selecionado e $80 \%$ dos trabalhos das referências, que são: Journal of Product Innovation Management, $R \& D$ Management, Research Policy e IEEE Transactions on Engineering Management. Tal conclusão pode ser confirmada pela relação das informações mostradas nas Figuras 8 e 11, onde se expõe que os 16 periódicos que contemplam os 25 artigos do Portfólio final são os mesmos que $27 \%$ dos 343 onde estão publicadas as referências.

Figura 14 - Periódicos com maior relevância no meio acadêmico

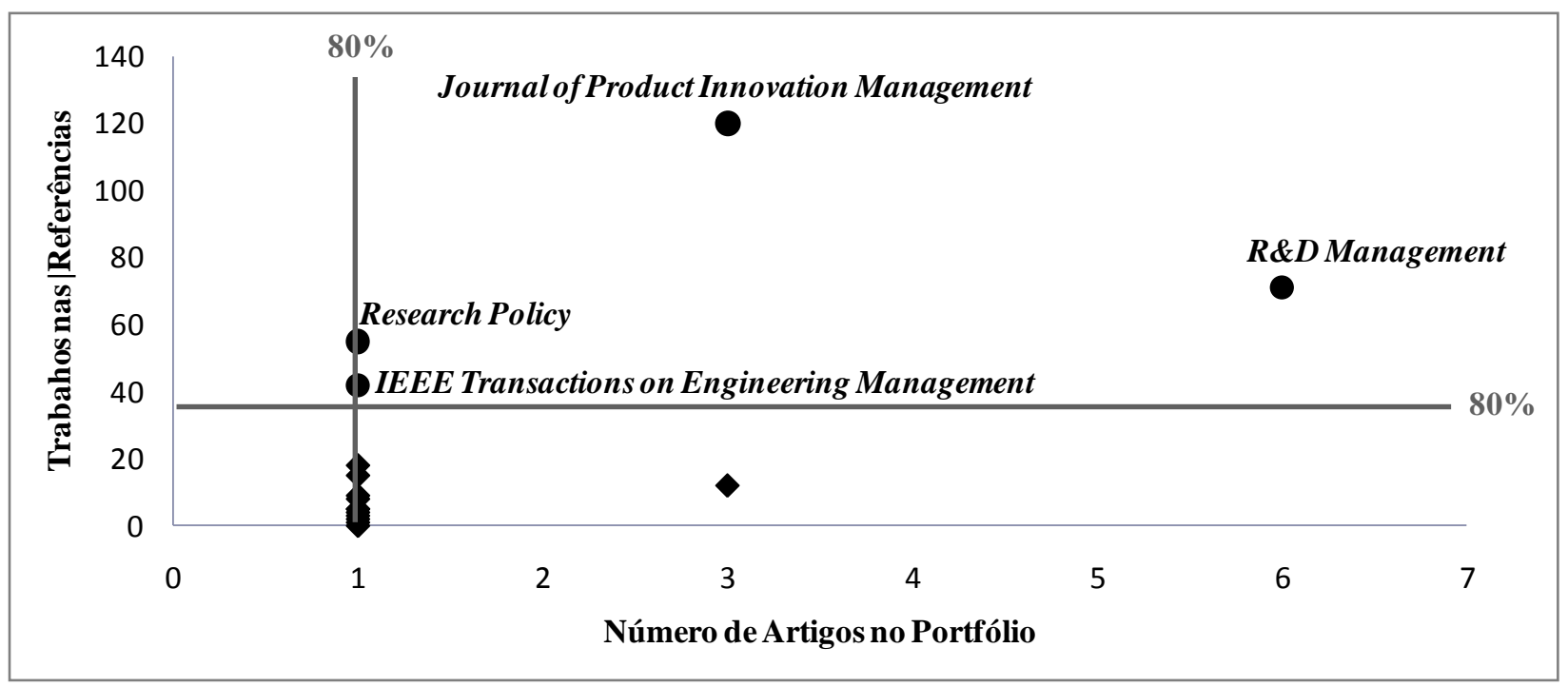

Fonte: Autoria própria (2011) 
Ao investigar os autores do Portfólio final, observa-se que todos os 64, apresentados na Figura 10, contribuem com $20 \%$ dos artigos utilizados como referências e, ao observar o Portfólio final selecionado, chega-se à conclusão de que há quatro artigos mais relevantes no meio acadêmico, apresentados na Figura 13, que contêm $80 \%$ do total de citações do Portfólio e $80 \%$ das contribuições dos autores nas referências. São eles:

- COOPER, R.; EDGETT, S.; KLEINSCHMIDT, E. Portfolio management for new product development: Results of an industry practices study. R\&D Management, v. 31, n. 4, p. 361-380, 2001.

- ADAMS, R.; BESSANT, J.; PHELPS, R. Innovation management measurement: A review. International Journal of Management Reviews, v. 8, n. 1, p. 21-47, 2006.

- HART, S.; HULTINK, E. J.; TZOKAS, N.; COMMANDEUR, H. R. Industrial companies' evaluation criteria in new product development gates. Journal of Product Innovation Management, v. 20, n. 1, p. 22-36, 2003.

- CALANTONE, R. J.; CHAN, K.; CUI, A. S. Decomposing product innovativeness and its effects on new product success. Journal of Product Innovation Management, v. 23, n. Compendex, p. 408-421, 2006.

Figura 15 - Artigos com maior relevância no meio acadêmico

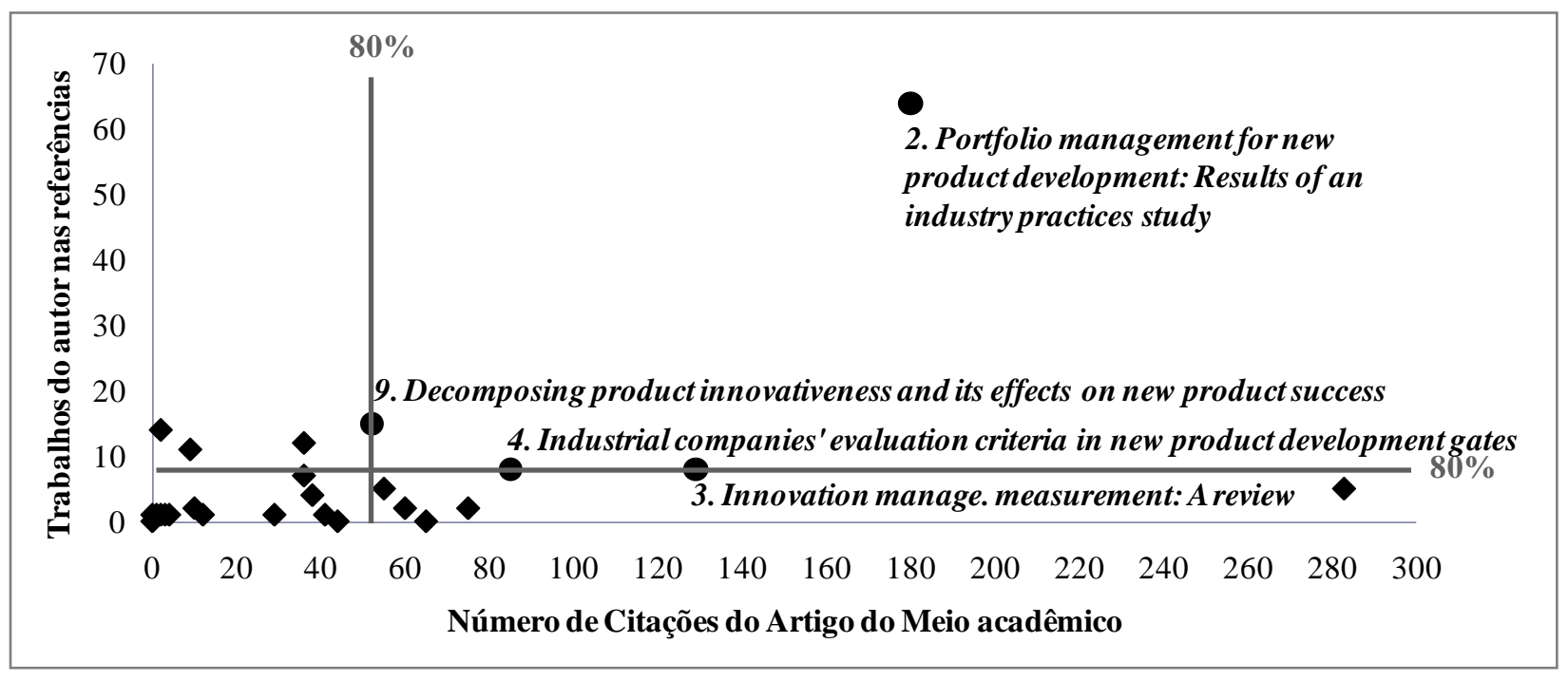

Fonte: Autoria própria (2011)

A conclusão dos artigos mais importantes pode ser confirmada pelo relacionamento das informações presentes nas Figuras 6 e 13. 


\subsection{Evidenciação dos periódicos e artigos com maior relevância acadêmica}

O Portfólio selecionado mostra artigos relevantes no meio acadêmico, com conteúdos que expressam o conhecimento existente a respeito de gestão $P \& D$ sob o ponto de vista do seu desempenho, pois i) o Portfólio é composto pelos artigos mais citados no meio acadêmico da área; ii) há distribuição homogênea em publicações nos últimos 10 anos; e, iii) os autores dos 25 artigos do Portfólio são os mesmos que contribuem com $20 \%$ de todos os trabalhos presentes nas referências bibliográficas, o que pode inferir por uma sinergia entre os trabalhos.

Além disso, o Portfólio é composto por três grupos de artigos: i) 13 artigos que possuem alinhamento de conteúdo com o tema de pesquisa; ii) grupo de oito artigos relevantes no meio acadêmico, por contribuírem ou com $80 \%$ do número de citações do Portfólio ou com $80 \%$ do número de vezes que os autores desses artigos apareceram nas referências bibliográficas; e, iii) os quatro principais artigos, evidenciados na Figura 16, que além de demonstrarem os melhores resultados quantitativos para os artigos selecionados, conforme Figura 15, estão também alinhadas com o tema da pesquisa.

Figura 16 - Características dos artigos com maior relevância no meio acadêmico

\begin{tabular}{|c|c|c|c|c|}
\hline $\begin{array}{l}\text { Título do } \\
\text { artigo }\end{array}$ & $\begin{array}{l}\text { 2 - Portfolio } \\
\text { management for new } \\
\text { product development: } \\
\text { Results of an industry } \\
\text { practices study }\end{array}$ & $\begin{array}{c}3 \text { - Innovation } \\
\text { management } \\
\text { measurement: A } \\
\text { review }\end{array}$ & $\begin{array}{c}4 \text { - Industrial } \\
\text { companies' } \\
\text { evaluation criteria in } \\
\text { new product } \\
\text { development gates }\end{array}$ & $\begin{array}{l}9 \text { - Decomposing } \\
\text { product } \\
\text { innovativeness and } \\
\text { its effects on new } \\
\text { product success }\end{array}$ \\
\hline $\begin{array}{l}\text { Análise do } \\
\text { escopo do } \\
\text { artigo }\end{array}$ & $\begin{array}{l}\text { O artigo defende que } \\
\text { fazer a gestão do } \\
\text { portfólio de } \\
\text { desenvolvimento de } \\
\text { novos produtos é um } \\
\text { fator crítico de } \\
\text { sucesso. Explicita os } \\
\text { métodos mais } \\
\text { populares para o meio } \\
\text { (COOPER, EDGETT } \\
\text { et al., 2001). }\end{array}$ & $\begin{array}{l}\text { O artigo descreve } \\
\text { um modelo para o } \\
\text { processo de gestão } \\
\text { da inovação. Faz } \\
\text { uma revisão da } \\
\text { literatura a fim de } \\
\text { mapear as condições } \\
\text { de contorno do } \\
\text { processo de } \\
\text { inovação (ADAMS, } \\
\text { BESSANT et al., } \\
\text { 2006). }\end{array}$ & $\begin{array}{l}\text { O artigo apresenta } \\
\text { resultados de estudo } \\
\text { sobre critérios de } \\
\text { avaliação usados em } \\
\text { diferentes etapas no } \\
\text { processo de } \\
\text { desenvolvimento de } \\
\text { novos produtos } \\
\text { (HART, HULTINK } \\
\text { et al., 2003). }\end{array}$ & $\begin{array}{c}\text { O artigo ilustra } \\
\text { como as medições } \\
\text { do sucesso de novos } \\
\text { produtos são } \\
\text { impactadas pelas } \\
\text { inovação nos } \\
\text { produtos e seu } \\
\text { alinhamento com o } \\
\text { mercado. } \\
\text { (CALANTONE, } \\
\text { CHAN et al., 2006). }\end{array}$ \\
\hline $\begin{array}{c}\text { Análise dos } \\
\text { autores }\end{array}$ & $\begin{array}{l}\text { Seus autores estão } \\
\text { entre os } 21 \text { maiores } \\
\text { contribuintes das } \\
\text { referências. }\end{array}$ & $\begin{array}{l}\text { Seus autores estão } \\
\text { entre os } 200 \text { maiores } \\
\text { contribuintes das } \\
\text { referências. }\end{array}$ & $\begin{array}{c}\text { Um dos autores está } \\
\text { entre os } 30 \text { maiores } \\
\text { das referências. }\end{array}$ & $\begin{array}{c}\text { Um dos autores está } \\
\text { entre os } 10 \text { maiores } \\
\text { das referências. }\end{array}$ \\
\hline $\begin{array}{c}\text { Análise do } \\
\text { periódico }\end{array}$ & $\begin{array}{l}\text { Publicada em } R \& D \\
\text { Management, um dos } \\
\text { principais periódicos. }\end{array}$ & $\begin{array}{c}\text { Publicada em } \\
\text { International } \\
\text { Journal of Manag. } \\
\text { Reviews, periódico } \\
\text { afim. }\end{array}$ & $\begin{array}{l}\text { Publicada em Journal } \\
\text { of Product Innovation } \\
\text { Management, um dos } \\
\text { principais periódicos. }\end{array}$ & $\begin{array}{l}\text { Publicada em } \\
\text { Journal of Product } \\
\text { Innovation } \\
\text { Management, um } \\
\text { dos principais } \\
\text { periódicos. }\end{array}$ \\
\hline
\end{tabular}

Fonte: Autoria própria (2011) 
Os quatro periódicos destacados na área tem seu quadro editorial condizente com o tema de pesquisa, conforme escopos descritos na Figura 17.

Figura 17 - Quadro editorial dos periódicos com maior relevância no meio acadêmico

\begin{tabular}{|c|c|c|c|c|}
\hline $\begin{array}{l}\text { Nome do } \\
\text { periódico }\end{array}$ & R\&D Management & $\begin{array}{c}\text { Journal of Product } \\
\text { Innovation } \\
\text { Management }\end{array}$ & Research Policy & $\begin{array}{c}\text { IEEE Transactions on } \\
\text { Engineering } \\
\text { Management }\end{array}$ \\
\hline $\begin{array}{c}\text { Quadro } \\
\text { editorial }\end{array}$ & $\begin{array}{c}\text { O periódico endereça } \\
\text { interesses de práticos } \\
\text { e teóricos a respeito } \\
\text { de pesquisa e } \\
\text { desenvolvimento } \\
\text { (P\&D) e gestão da } \\
\text { inovação. Cobre } \\
\text { tópicos de pesquisa, } \\
\text { desenvolvimento, } \\
\text { design, inovação e } \\
\text { questões estratégicas, } \\
\text { examinando contextos } \\
\text { social, econômico e } \\
\text { ambiental (R\&D } \\
\text { MANAGEMENT, } \\
\text { 2011). }\end{array}$ & $\begin{array}{c}\text { O periódico abrange } \\
\text { estruturas teóricas e } \\
\text { práticas em gestão } \\
\text { da inovação de } \\
\text { produtos e tem } \\
\text { como público alvo } \\
\text { do conhecimento } \\
\text { que oferece } \\
\text { executivos, } \\
\text { consultores, } \\
\text { acadêmicos e } \\
\text { estudantes de } \\
\text { inovação } \\
\text { (JOURNAL OF } \\
\text { PRODUCT } \\
\text { INNOVATION } \\
\text { MANAGEMENT, } \\
\text { 2011). }\end{array}$ & $\begin{array}{l}\text { O periódico examina } \\
\text { empírica e } \\
\text { teoricamente, em } \\
\text { paralelo, a interação } \\
\text { entre inovação, } \\
\text { tecnologia e } \\
\text { pesquisa, com } \\
\text { aspectos } \\
\text { econômicos, sociais, } \\
\text { políticos e } \\
\text { organizacionais. } \\
\text { Os artigos têm } \\
\text { implicações políticas } \\
\text { ou gerenciais } \\
\text { (RESEARCH } \\
\text { POLICY, 2011). }\end{array}$ & $\begin{array}{l}\text { O periódico engloba } \\
\text { aplicações da gestão } \\
\text { de ciências e } \\
\text { tecnologias em } \\
\text { organizações, } \\
\text { incluindo as políticas } \\
\text { de tecnologia, sua } \\
\text { transferência, } \\
\text { pesquisa, } \\
\text { desenvolvimento, } \\
\text { avaliação, produção e } \\
\text { afins (IEEE } \\
\text { TRANSACTIONS } \\
\text { ON ENGINEERING } \\
\text { MANAGEMENT, } \\
\text { 2011). }\end{array}$ \\
\hline
\end{tabular}

Fonte: Autoria própria (2011)

Por fim, percebe-se que três dos quatro artigos relevantes na amostra estão publicados em dois dos quatro periódicos destacados na área.

\subsection{Análise sistêmica}

A análise sistêmica é um processo científico utilizado para proceder à análise crítica dos artigos do PB a partir dos pressupostos (lentes) da afiliação teórica de Avaliação de Desempenho adotada, a fim identificar em cada pressuposto as possibilidades de futuras investigações diante das lacunas identificadas (ENSSLIN et al, 2010a e b). Tal processo tem ganhado importância na literatura sobre gestão (DENYER, NEELY, 2004) e é realizado sobre um tema contendo critérios explícitos de seleção do conteúdo e de análise, de forma que outros pesquisadores possam avaliar a qualidade da revisão ou executá-la novamente (TRANFIELD, DENYER, SMART, 2003; TASCA et al, 2010).

O presente processo de análise sistêmica está realizado para a afiliação teórica de mensuração de performance ou Avaliação de Desempenho da gestão de $\mathrm{P} \& \mathrm{D}$, a qual é explicada por seis pressupostos ou lentes. A análise sistêmica estuda os artigos do Portfólio 
um a um, evidenciando os pontos fortes e fracos de cada artigo em cada pressuposto e também no conjunto de artigos em cada lente.

Tais pressupostos (lentes) provêm do propósito de Avaliação de Desempenho em construir conhecimento do contexto que permita tomar decisões com compreensão de suas consequências, fundamentado naquilo que o decisor julga importante (ENSSLIN, MONTIBELLER, NORONHA, 2001; ENSSLIN et al, 2010b). Assim como em qualquer contexto específico, a Avaliação de Desempenho, no processo de gestão de $\mathrm{P} \& \mathrm{D}$, compreende a identificação, organização, mensuração e integração dos seus aspectos relevantes, diagnosticando a situação atual e gerando procedimento para melhorar o desempenho (LACERDA, ENSSLIN, ENSSLIN, 2011; ENSSLIN, ENSSLIN, 2010a; ENSSLIN, et a., 2010b). Portanto, para cada um das seis lentes, foram desenvolvidas diretrizes que norteiam as análises:

a) LENTE 1: Conceito de Avaliação de Desempenho

- Qual o conceito de AD apresentado no artigo?

- Qual a filiação teórica?

b) LENTE 2: Singularidade de atores, contex to e momento

- Reconhece que o contexto é único?

- Reconhece os atores que participam do contexto?

c) LENTE 3: Processo para identificar os aspectos relevantes

- Como acontece o processo para identificar as variáveis importantes?

- Como o processo lida com os limites de conhecimento do gestor?

- Como os valores e preferências do gestor interferem na identificação?

d) LENTE 4: Mensuração dos aspectos relevantes

- Qual a descrição das escalas utilizadas?

- As escalas atendem às propriedades de mensurabilidade, operacionalidade, homogeneidade e inteligibilidade?

- As escalas reconhecem a ordinalidade e a cardinalidade?

e) LENTE 5: Integração das escalas

- Realiza a integração das escalas?

- Como são apresentadas as questões ao decisor para determinação das constantes de integração?

f) LENTE 6: Gestão

- Gera aperfeiçoamento a partir do conhecimento construído?

- Permite diagnosticar a situação atual? 
- Disponibiliza processo para gerar ações de aperfeiçoamento?

\subsubsection{Conceito}

A gestão de $P \& D$ na perspectiva adotada assume que seu monitoramento e aperfeiçoamento somente podem ser realizados em forma fundamentada e transparente se tiver sua performance avaliada e medida em termos dos parâmetros que a explicam.

Para os artigos do Portfólio selecionado, tem-se que os 25 artigos descrevem "o que", "como" e "para que" se propõem a avaliar o contexto da Gestão de P\&D, podendo ser classificados com cinco enfoques diferentes, conforme a Figura 18.

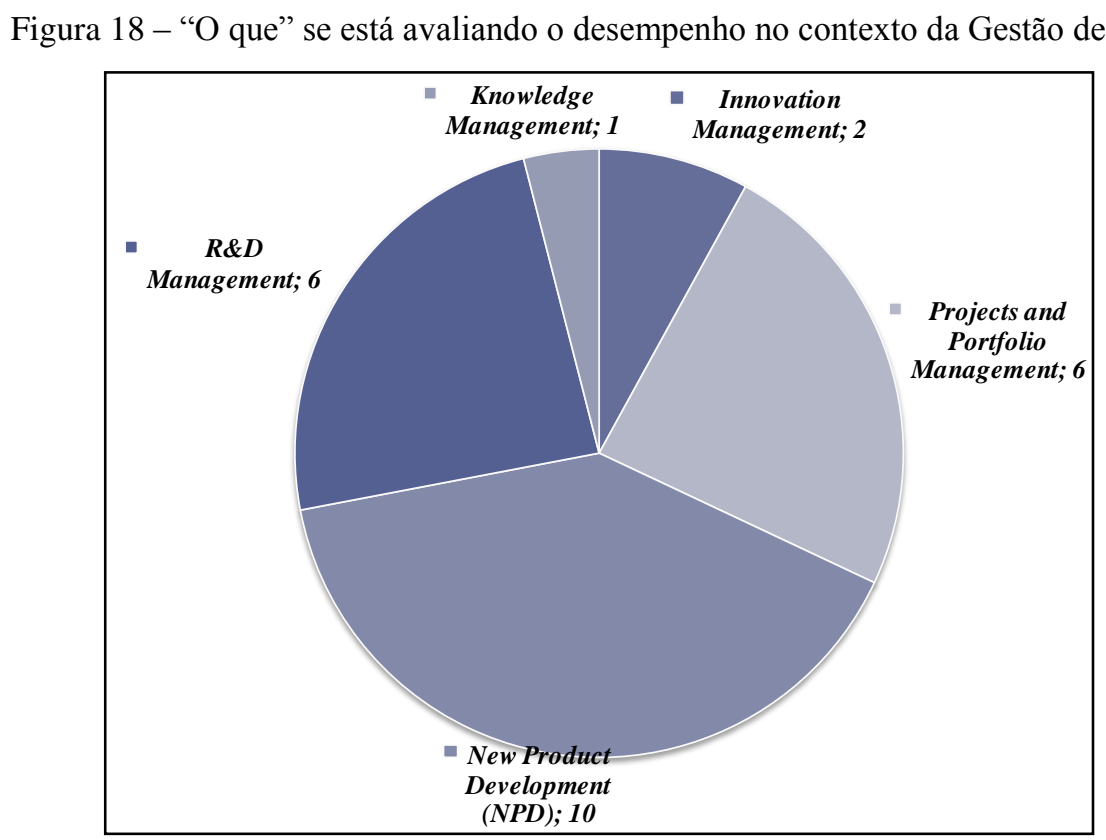

Fonte: Autoria própria (2011)

Há dez artigos que abordam o desempenho em Desenvolvimento de Novos Produtos (PILLAI, JOSHI, RAO, 2002; HART et al, 2003; CORMICAN, O'SULLIVAN, 2004; MALLICK, SCHROEDER, 2005; SANTIAGO, BIFANO, 2005; CALANTONE, CHAN, CUI, 2006; SCHMIDT, SARANGEE, MONTOYA, 2009; VUOLLE, LÖNNQVIST, VAN DER MEER, 2009; CEDERGREN, WALL, NORSTRM, 2010; PANIZZOLO, BIAZZO, GARENGO, 2010); seis se propõem a avaliar o Gerenciamento de Projetos e Portfólios no contexto do P\&D (COOPER, EDGETT, KLEINSCHMIDT, 2001; MIKKOLA, 2001; VERMA, SINHA, 2002; EILAT, GOLANY, SHTUB, 2008; ELMQUIST, LE MASSON, 2009; WANG, LIN, HUANG, 2010), dois realizam a avaliação da Gestão da Inovação (HAGEDOORN, CLOODT, 2003; ADAMS, BESSANT, PHELPS, 2006), um deles enfoca a 
Gestão do Conhecimento (CHEN, HUANG, CHENG, 2009); os demais seis artigos se propõem a avaliar o processo de Gestão de P\&D (BREMSER, BARSKY, 2004; VON ZEDTWITZ, GASSMANN, BOUTELLIER, 2004; GARCÍA-VALDERRAMA, MULEROMENDIGORRI， 2005; LIN，CHEN，2005; GARCÍA-VALDERRAMA， MULEROMENDIGORRI, REVUELTA-BORDOY, 2008; CHIESA, FRATTINI, LAZZAROTTI, 2009). Há um consenso entre os artigos de que o objetivo final, ao fazer a avaliação, é melhorar o desempenho do contexto.

Por ser a gestão de P\&D passível de ser realizada segundo qualquer uma das perspectivas (descritivista; normativista; prescritivista e construtivista) (ROY, 1993; ROY, VANDERPOOTEN, 1995; 1996; ENSSLIN, ENSSLIN, DUTRA, 2000), busca-se nessa lente identificar qual a filiação teórica do autor e se ele está consciente delas e assume a sua abordagem a fim de entender se isso é um dos pontos fortes ou uma lacuna que, se modificada, poderá contribuir para a melhoria da pesquisa. Tais visões são compreendidas como: i) a visão descritivista é a observação do mundo como este se apresenta e não emite julgamento sobre a realidade descrita; ii) a normativista está associada à visão do mundo através de processos idealizados (o problema está contido no modelo) e defende o uso de fórmulas matemáticas manipuladas pelo decisor; iii) a visão prescritivista sugere que o modelo seja construído a partir dos dados disponibilizados pelo decisor e as soluções se aplicam para quaisquer contextos; e, iv) e a construtivista consiste em construir uma visão de mundo através do processo decisório, onde sua estruturação avança de forma interativa e de modo coerente com os objetivos e valores do decisor e com o contexto (VINCKE, 1989).

Dos 25 artigos do Portfólio, apenas cinco artigos deixam evidências que são filiados ao construtivismo, porém não estão conscientes disso (MIKKOLA, 2001; PILLAI, JOSHI, RAO, 2002; SANTIAGO, BIFANO, 2005; ELMQUIST, LE MASSON, 2009; WANG, LIN, HUANG, 2010). Os autores do presente trabalho entendem que a gestão de P\&D é um processo complexo e exige modelos multicritérios para avaliar seu desempenho (GRIFFIN e PAGE, 1993; HULTINK, ROBBEN, 1995; COOPER, EDGETT, KLEINSCHMIDT, 2001; MIKKOLA, 2001; VERMA, SINHA, 2002; HAGEDOORN, CLOODT, 2003; BREMSER e BARSKY，2004; LIN，CHEN，2005; ADAMS，BESSANT，PHELPS， 2006; EILAT, GOLANY, SHTUB, 2008). As pesquisas evidenciam que as três primeiras visões têm seus resultados restritos e comprometidos e que a visão construtivista é a recomendável para essas situações (ROY, 1994; 2005; ENSSLIN, DE CAMPOS, 2006; DE MORAES et al, 2010; ENSSLIN, ENSSLIN, 2010; ENSSLIN et al, 2010b). 


\subsubsection{Singularidade}

A segunda lente de análise da revisão sistêmica busca entender se os modelos de Avaliação de Desempenho da Gestão de P\&D, presentes nos artigos selecionados, reconhecem a singularidade do contexto decisório, de seus atores e do momento (ENSSLIN, MONTIBELLER, NORONHA, 2001).

Para a Análise Sistêmica da lente Singularidade do contexto, foram classificados os artigos do Portfólio Bibliográfico, conforme Figura 19, em: artigos que reconhecem que o modelo desenvolvido somente pode ser aplicado para essa organização; e artigos que desenvolvem o modelo para uma organização e posteriormente o utilizam também para outras.

Figura 19 - Singularidade do Contexto dos artigos do Portfólio

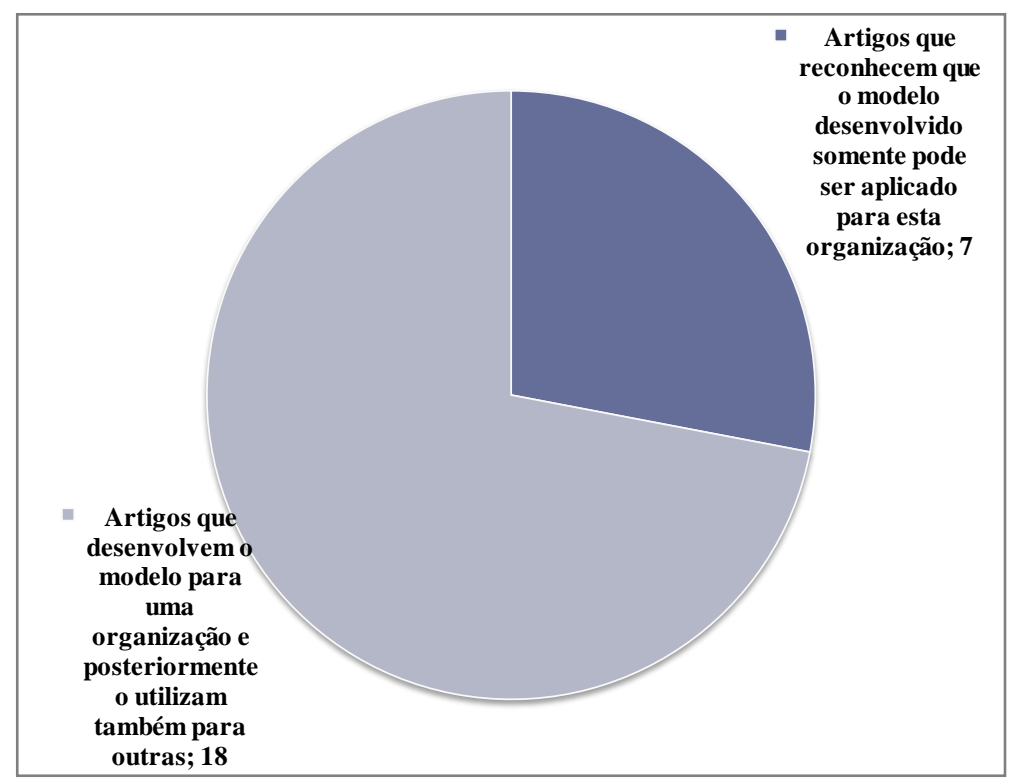

Fonte: Autoria própria (2011)

Dos 25 artigos selecionados para essa análise sistêmica, contata-se que $72 \%$ dos trabalhos não atendem à singularidade do conceito ou não explicitam posicionamento a respeito (COOPER, EDGETT, KLEINSCHMIDT, 2001; VERMA, SINHA, 2002; HAGEDOORN, CLOODT, 2003; BREMSER, BARSKY， 2004; CORMICAN, O’SULLIVAN, 2004; VON ZEDTWITZ, GASSMANN, BOUTELLIER, 2004; GARCÍAVALDERRAMA, MULERO-MENDIGORRI, 2005; LIN, CHEN, 2005; MALLICK, SCHROEDER, 2005; SANTIAGO, BIFANO, 2005; CALANTONE, CHAN, CUI, 2006; GARCÍA-VALDERRAMA， MULERO-MENDIGORRI， REVUELTA-BORDOY， 2008; CHEN, HUANG, CHENG, 2009; SCHMIDT, SARANGEE, MONTOYA, 2009; VUOLLE, 
LÖNNQVIST, VAN DER MEER, 2009; CEDERGREN, WALL, NORSTRM, 2010; PANIZZOLO, BIAZZO, GARENGO, 2010; WANG, LIN, HUANG, 2010). Tais autores desenvolveram suas teorias baseados, principalmente, em análises estatísticas de revisões da literatura (HAGEDOORN, CLOODT, 2003), de amostras de organizações consideradas referência no assunto (COOPER, EDGETT, KLEINSCHMIDT, 2001; CORMICAN, O'SULLIVAN, 2004; LIN, CHEN, 2005; CALANTONE, CHAN, CUI, 2006) ou de opiniões de especialistas do tema (GARCÍA-VALDERRAMA, MULERO-MENDIGORRI, REVUELTA-BORDOY, 2008). Porém as limitações desses modelos vêm à tona devido à sua generalização (ADAMS, BESSANT, PHELPS, 2006) e, tratando-se da Gestão de P\&D, autores alertam que modelos bem sucedidos em algumas organizações podem levar ao fracasso em outras (HAUSER, ZETTELMEYER, 1997), o que pode ser entendido como seu reconhecimento da importância de ter em conta sua singularidade, apesar de posteriormente não a praticarem.

Os autores do presente trabalho compartilham a posição dos sete artigos que atendem à singularidade do contexto (MIKKOLA, 2001; PILLAI, JOSHI, RAO, 2002; HART et al, 2003; ADAMS, BESSANT, PHELPS, 2006; EILAT, GOLANY, SHTUB, 2008; CHIESA, FRATTINI, LAZZAROTTI, 2009; ELMQUIST, LE MASSON, 2009). Dentre eles se reconhece a necessidade de desdobramento da estratégia da empresa - missão, visão e valores -(HART et al, 2003) para uma efetiva avaliação do contexto.

Para a Análise Sistêmica da lente Singularidade do gestor (decisor) do contexto foram classificados os artigos do Portfólio Bibliográfico em artigos que reconhecem que o modelo deve ser construído para o gestor do problema e o identificam no trabalho; artigos que reconhecem que o modelo deve ser construído a partir do gestor, mas ao operacionalizar o modelo não o identificam e/ou não trabalham a partir dele; artigos que não reconhecem que o modelo deve ser construído a partir do gestor. A figura 20 apresenta os resultados desta pesquisa.

Tem-se que $72 \%$ dos artigos do Portfólio não atendem à Singularidades dos atores do problema (COOPER, EDGETT, KLEINSCHMIDT, 2001; VERMA, SINHA, 2002; HAGEDOORN, CLOODT, 2003; HART et al, 2003; BREMSER, BARSKY, 2004; CORMICAN, O'SULLIVAN, 2004; VON ZEDTWITZ, GASSMANN, BOUTELLIER, 2004; GARCÍA-VALDERRAMA， MULERO-MENDIGORRI，2005; MALLICK, SCHROEDER, 2005; ADAMS, BESSANT, PHELPS, 2006; CALANTONE, CHAN, CUI, 2006; GARCÍA-VALDERRAMA， MULERO-MENDIGORRI， REVUELTA-BORDOY, 2008; CHEN，HUANG，CHENG，2009; CHIESA，FRATTINI，LAZZAROTTI，2009; 
SCHMIDT, SARANGEE, MONTOYA, 2009; VUOLLE, LÖNNQVIST, VAN DER MEER, 2009; CEDERGREN, WALL, NORSTRM, 2010; PANIZZOLO, BIAZZO, GARENGO, 2010), 20\% reconhecem a necessidade da Singularidade, mas não explicitam como o fazem (LIN, CHEN, 2005; SANTIAGO, BIFANO, 2005; EILAT, GOLANY, SHTUB, 2008; SCHMIDT, SARANGEE, MONTOYA, 2009; WANG, LIN, HUANG, 2010) e 8\% são singulares e descrevem a operacionalização (MIKKOLA, 2001; PILLAI, JOSHI, RAO, 2002).

Figura 20 - Singularidade dos Atores dos artigos do Portfólio

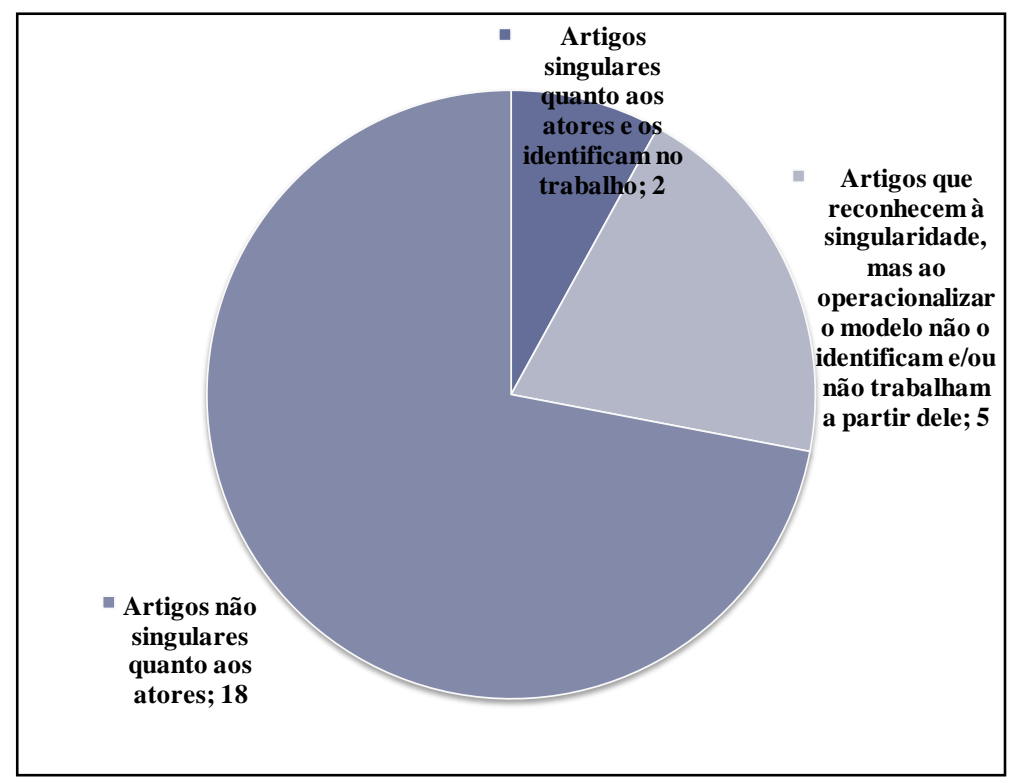

Fonte: Autoria própria (2011)

Os autores do presente trabalho reiteram que o processo de gestão de P\&D é um problema complexo e combina particularidades de cada organização a respeito de inovação, tecnologia, pesquisas básica e aplicada, desenvolvimento de produtos, gerenciamento de projetos e Portfólios, gestão de conhecimento dentre outros. Essas situações requerem abordagens de Avaliação de Desempenho focadas nas preferências de um ou mais decisores e que os demais afetados pela decisão possam participar de alguma maneira do processo (SKINNER, 1986; KEENEY, 1992; BANA E COSTA, ENSSLIN et al, 1999; GIFFHORN, et al, 2010b; ENSSLIN, DUTRA, ENSSLIN, 2000).

\subsubsection{Processo para identificar os aspectos relevantes}

A lente abordada nesta seção está concentrada em analisar a forma pela qual os artigos selecionados se propõem a identificar os critérios usados para avaliação e tomar 
conhecimento de como os decisores são envolvidos nessa atividade, principalmente quanto à sua limitação de conhecimento e às suas preferências e valores pessoais.

Em uma visão geral do Portfólio de artigos, pode-se classificá-los em quatro grandes frentes de processos de identificação dos critérios, conforme a Figura 21, em artigos que utilizam benchmarking com organizações para identificar os critérios; artigos que utilizam revisões literárias; artigos que partem de opiniões de especialistas; e artigos que identificam os aspectos pelo desdobramento estratégico.

Figura 21 - Processos para identificar aspectos relevantes presentes nos artigos do Portfólio

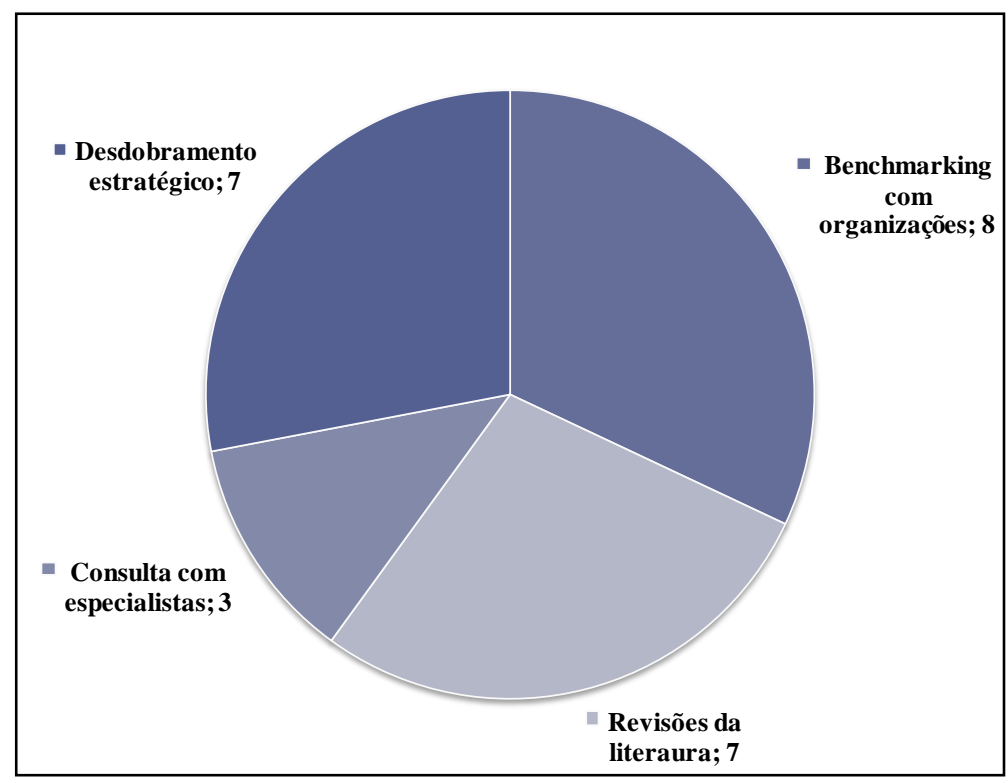

Fonte: Autoria própria (2011)

Primeiro, há modelos que selecionam os aspectos por meio de benchmarking com outras organizações, ou seja, visitas e entrevistas a uma amostra selecionada de empresas e consideradas referências no seu ramo de atuação. Há oito trabalhos que adotam esse processo no Portfólio selecionado (COOPER, EDGETT, KLEINSCHMIDT, 2001; VERMA, SINHA, 2002; HAGEDOORN, CLOODT, 2003; HART et al, 2003; CORMICAN, O'SULLIVAN, 2004; VON ZEDTWITZ, GASSMANN, BOUTELLIER, 2004; CHEN, HUANG, CHENG, 2009), dos quais um exige que os critérios se encaixem nas perspectivas do BSC (KAPLAN, NORTON, 1992; CHEN, HUANG, CHENG, 2009). Defende-se que, como muitos estudos usam diferentes indicadores e aspectos, se faz importante realizar uma análise estatística dos dados para então chegar a um cenário final (HAGEDOORN, CLOODT, 2003). Também se julga relevante a aplicação de questionários para auxílio na coleta de informações dos critérios (COOPER, EDGETT, KLEINSCHMIDT, 2001) ou o uso de instrumentos de registro digital das entrevistas (VERMA, SINHA, 2002). 
No segundo conjunto, há sete artigos que evidenciam um processo baseado em revisões da literatura para identificação dos aspectos relevantes e também das métricas que devem avaliar o desempenho do processo de gestão de P\&D (BREMSER, BARSKY, 2004; GARCÍA-VALDERRAMA, MULERO-MENDIGORRI, 2005; ADAMS, BESSANT, PHELPS, 2006; GARCÍA-VALDERRAMA，MULERO-MENDIGORRI, REVUELTABORDOY, 2008; CHIESA, FRATTINI, LAZZAROTTI, 2009; VUOLLE, LÖNNQVIST, VAN DER MEER, 2009; PANIZZOLO, BIAZZO, GARENGO, 2010). Destes, dois trabalhos utilizam as perspectivas do BSC (BREMSER, BARSKY, 2004; GARCÍAVALDERRAMA, MULERO-MENDIGORRI, REVUELTA-BORDOY, 2008) e um préestabelece outras dimensões escolhidas pelos autores (GARCÍA-VALDERRAMA, MULERO-MENDIGORRI, 2005).

Outros três artigos contêm modelos que identificam seus aspectos importantes por meio de consultas com especialistas no assunto abordado (MALLICK, SCHROEDER, 2005; CALANTONE, CHAN, CUI, 2006; CEDERGREN, WALL, NORSTRM, 2010).

O grupo restante é composto por sete artigos que defendem a identificação de critérios pelo desdobramento da estratégia da empresa (MIKKOLA, 2001; PILLAI, JOSHI, RAO, 2002; LIN, CHEN, 2005; SANTIAGO, BIFANO, 2005; EILAT, GOLANY, SHTUB, 2008; ELMQUIST, LE MASSON, 2009; WANG, LIN, HUANG, 2010), sendo que dois dos modelos utilizam as perspectivas do BSC (EILAT, GOLANY, SHTUB, 2008; WANG, LIN, HUANG, 2010), três pré-estabelecem dimensões (MIKKOLA, 2001; PILLAI, JOSHI, RAO, 2002; LIN, CHEN, 2005) e outros dois fazem por meio de um estudo de caso específico (SANTIAGO, BIFANO, 2005; ELMQUIST, LE MASSON, 2009). Para tais autores, quem deve definir os aspectos são os gestores e a importância de cada fator deve ser explicitada. Contudo, nenhum desses artigos apresenta um modelo que considera que os gestores têm conhecimentos limitados e precisam de ajuda para desenvolvê-lo e, assim, identificar os aspectos de forma participativa.

Historicamente, os modelos de $\mathrm{AD}$ costumavam utilizar critérios da dimensão financeira. No entanto, pesquisas nas décadas de 1980 e 1990 demonstram as limitações dessa visão e afirmam que esses modelos devem envolver outros aspectos a fim de efetivamente suportar uma organização, como medidas de tempos, qualidade, flexibilidade, inovação, etc. (KAPLAN, 1983; HALL, JOHNSON, TURNEY, 1990; ECCLES, 1991; NANNI, A. J.; DIXON, J. R.; VOLLMANN, 1992; BEAMON, 1999). Estudos empíricos demonstram que a estratégia organizacional está relacionada com expansão dos tradicionais critérios para novas medidas de desempenho (BANKER, POTTER, SCHROEDER, 1993; 
ABERNETHY e LILLIS, 1995; PERERA, HARRISON, POOLE, 1997; FULLERTON e MCWATTERS, 2002; BAINES e LANGFIELD-SMITH, 2003). Atualmente, um modelo de Avaliação de Desempenho deve ter suas variáveis amplamente distribuídas, capazes de envolver inúmeras dimensões: objetivas versus subjetivas, internas versus externas e financeiras versus não financeiras (HENRI, 2006).

Nesse contexto, abordando o processo de gestão de $\mathrm{P} \& \mathrm{D}$, deve-se reconhecer que os critérios utilizados na avaliação de um problema representam as propriedades operacionais do contexto que estão relacionados com os valores e preferências de um decisor (ROY e VANDERPOOTEN, 1996). Para os autores do presente trabalho, em problemas complexos como a gestão de $\mathrm{P} \& \mathrm{D}$, essa identificação requer a construção de entendimento no decisor sobre o problema e sua participação para que os critérios selecionados estejam alinhados com os objetivos estratégicos do gestor (ENSSLIN, 2010).

\subsubsection{Processo de mensuração dos aspectos relevantes}

A próxima lente do processo de análise sistêmica busca identificar as escalas utilizadas nos trabalhos selecionados. Conforme a Figura 22, os artigos são divididos em artigos que não comentam a respeito do processo de mensuração; artigos que utilizam escalas nominais (qualitativas); artigos com escalas ordinais (qualitativas); artigos que mensuram por meio de escalas de intervalo (quantitativas); e artigos que utilizam escalas de razão (quantitativas).

Figura 22 - Processos de mensuração dos aspectos relevantes presentes nos artigos do Portfólio

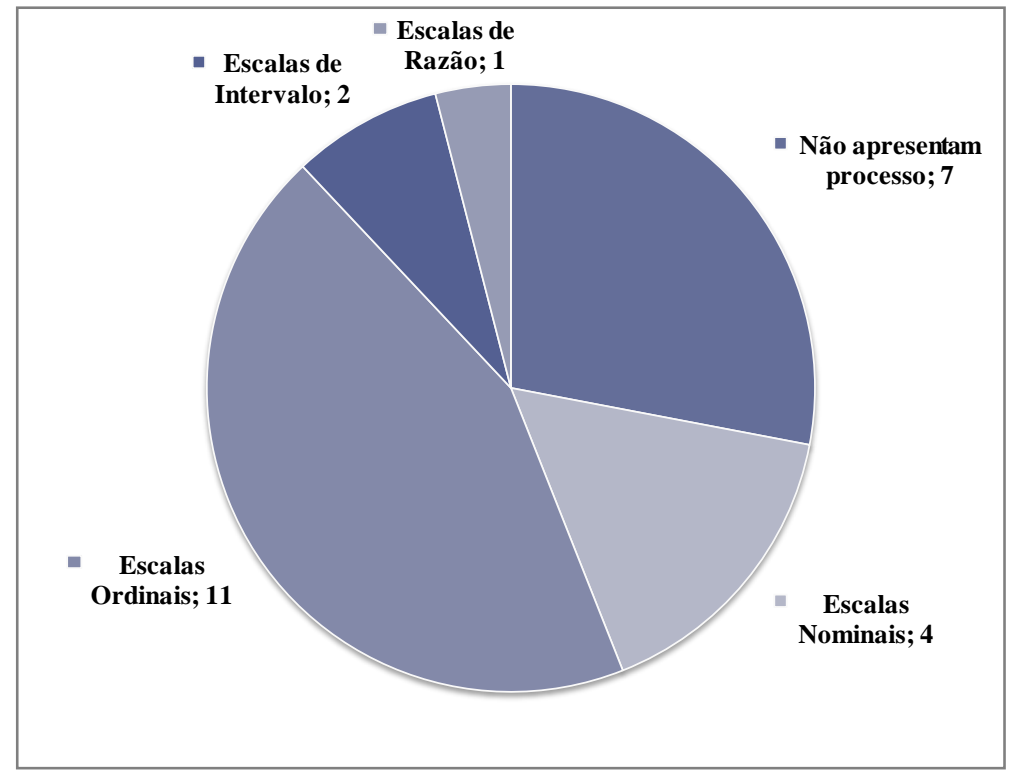

Fonte: Autoria própria (2011) 
Observa-se que 32\% dos artigos do Portfólio não apresentam processo para mensurar os aspectos relevantes (BREMSER, BARSKY, 2004; VON ZEDTWITZ, GASSMANN, BOUTELLIER，2004; GARCÍA-VALDERRAMA， MULERO-MENDIGORRI，2005; ADAMS, BESSANT, PHELPS, 2006; GARCÍA-VALDERRAMA, MULEROMENDIGORRI， REVUELTA-BORDOY， 2008; CHEN， HUANG，CHENG， 2009; ELMQUIST, LE MASSON, 2009; VUOLLE, LÖNNQVIST, VAN DER MEER, 2009).

Há quatro artigos entre os 25 que utilizam de Escalas Nominais (HAGEDOORN, CLOODT, 2003; HART et al, 2003; CHIESA, FRATTINI, LAZZAROTTI, 2009; CEDERGREN, WALL, NORSTRM, 2010). A Escala Nominal (ou Verbal) é qualitativa e é a mais limitada das escalas, pois atribui nomes ou números para as opções e se baseia apenas numa categorização para os diferentes aspectos, não estabelecendo qualquer relação de grandeza ou ordem (ENSSLIN, ENSSLIN, 2010).

Há onze artigos que mensuram seus aspectos por meio de Escalas Ordinais (COOPER, EDGETT, KLEINSCHMIDT, 2001; MIKKOLA, 2001; VERMA, SINHA, 2002; CORMICAN, O’SULLIVAN, 2004; LIN, CHEN, 2005; MALLICK, SCHROEDER, 2005; SANTIAGO, BIFANO, 2005; CALANTONE, CHAN, CUI, 2006; EILAT, GOLANY, SHTUB, 2008; SCHMIDT, SARANGEE, MONTOYA, 2009; WANG, LIN, HUANG, 2010). A Escala Ordinal ordena os níveis de desempenho qualitativamente, indicando a ordem de preferência dos itens associados a um objetivo e permite as operações de contagem, frequência, moda e mediana (CHISNALL, 1973), mas não explicita as diferenças de atratividade de cada nível de desempenho. Nesse grupo, seis artigos utilizam o tipo Likert (COOPER, EDGETT, KLEINSCHMIDT, 2001; VERMA, SINHA, 2002; CORMICAN, O'SULLIVAN, 2004; MALLICK, SCHROEDER, 2005; CALANTONE, CHAN, CUI, 2006; WANG, LIN, HUANG, 2010), sendo este comum devido à sua facilidade de aplicação, porém limitado pela sua ambiguidade.

Um artigo apresenta Escalas de Intervalo em seu conteúdo (PANIZZOLO, BIAZZO, GARENGO, 2010), a qual atribui números que representem a diferença quantitativa entre alternativas de um critério e possui o ponto zero arbitrário, não sendo sua origem (ENSSLIN, ENSSLIN, 2010; DE MORARES et al, 2010). Esse mesmo trabalho apresenta escalas cardinalizadas por meio do AHP (Analytic Hierarchy Process).

Por último, há um artigo que mensura seus critérios com Escalas de Razão (PILLAI, JOSHI, RAO, 2002), que ordenam as unidades quanto à característica mensurada, possuem 
uma unidade de medida constante e uma origem. A Escala de Razão é quantitativa e permite todas as operações matemáticas (ENSSLIN, ENSSLIN, 2010).

Essa lente justifica sua importância, pois os autores deste trabalho compartilham com os estudos de que as escalas devem atender a seis propriedades para terem respaldo científico (KEENEY, 1992; GIFFHORN et al, 2010):

a) Mensurabilidade: significa que o juízo de valor do decisor deve ser refletido na escala, isto é mensurar o que é importante em determinado aspecto em vez de utilizar as informações que são mais facilmente obtidas.

b) Operacionalidade: defende que se faz necessário garantir sua implementação, ou seja, a escala deve ser possível de ser operacionalizada.

c) Homogeneidade: a escala deve possuir em todos os níveis de mensuração as mesmas propriedades da informação.

d) Inteligibilidade: diz respeito a não ambiguidade das escalas, que significa que se obtém o mesmo resultado no caso dos aspectos serem medidos diferentes indivíduos.

e) Permitir distinguir o desempenho melhor e pior: a escala deve informar de forma explícita e não ambígua o conteúdo que diferencia um nível do outro.

f) Respeitar as propriedades das escalas ordinais: defende que as escalas ordenem os níveis em um dado critério de acordo com a preferência do decisor.

Além disso, as escalas devem considerar a cardinalidade, ou seja, a diferença de atratividade entre cada nível de performance (BARZILAI, 1997). Isso significa que a função de valor de cada escala deve ser explícita de acordo com as preferências do decisor (KEENEY, 1992). Diante disso, essa lente se encontra debilitada nos artigos do Portfólio selecionado.

\subsubsection{Integração das escalas}

A presente lente do processo de análise dos artigos se concentra em, primeiro, descobrir se o artigo selecionado faz a integração dos indicadores e, posteriormente, se estabelece compensações, fundamentando e mensurando sua contribuição para a avaliação global do contexto. Para essa lente, dividem-se os 25 artigos do Portfólio em oito diferentes grupos, conforme a Figura 23. 
Figura 23 - Processos de integração das escalas presentes nos artigos do Portfólio

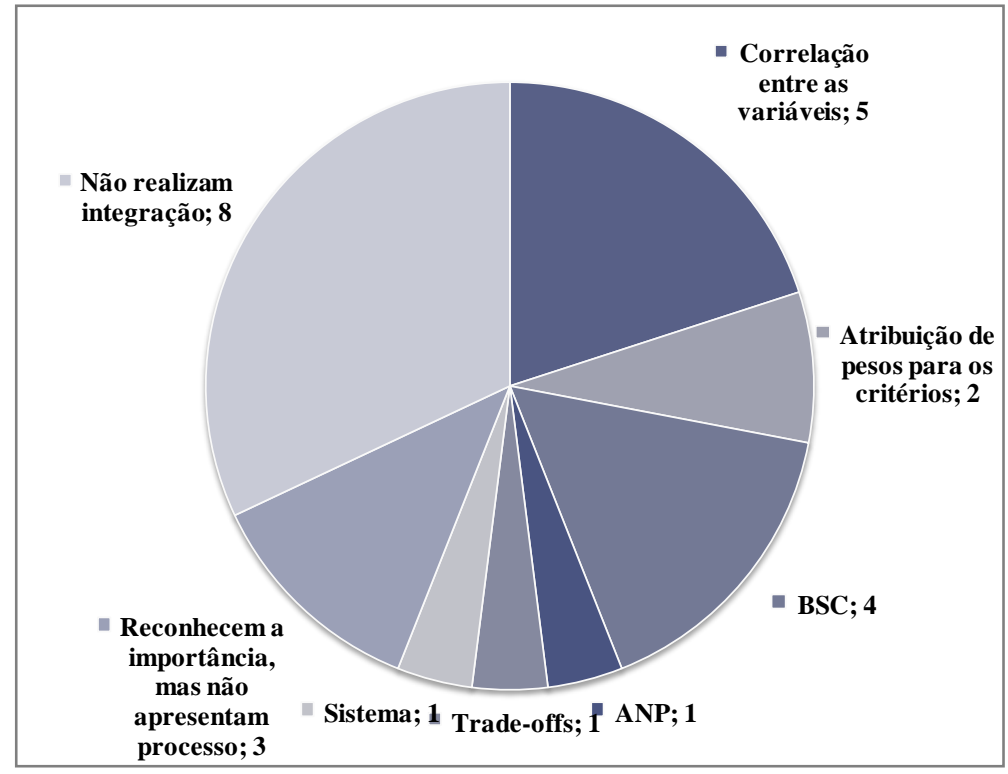

Fonte: Autoria própria (2011)

Observa-se que 32\% dos trabalhos selecionados não realizam integração ou não apresentaram conteúdo a respeito (CORMICAN, O’SULLIVAN, 2004; VON ZEDTWITZ, GASSMANN， BOUTELLIER， 2004; GARCÍA-VALDERRAMA， MULEROMENDIGORRI, 2005; SANTIAGO, BIFANO, 2005; ADAMS, BESSANT, PHELPS, 2006; SCHMIDT, SARANGEE, MONTOYA, 2009; VUOLLE, LÖNNQVIST, VAN DER MEER, 2009; PANIZZOLO, BIAZZO, GARENGO, 2010) e dos 68\% que reconhecem a importância da integração dos indicadores, três deles não explicitam em seu conteúdo como fazê-la (VERMA, SINHA, 2002; HART et al, 2003; EILAT, GOLANY, SHTUB, 2008).

Há cinco trabalhos que utilizam análise de correlação entre as variáveis (MIKKOLA, 2001; HAGEDOORN, CLOODT, 2003; LIN, CHEN, 2005; MALLICK, SCHROEDER, 2005; CEDERGREN, WALL, NORSTRM, 2010), como a utilização da medida de KMO (Kaiser-Meyer-Olkin) e da medida de adequação de amostragem MAS (Measure Adequacy Sample) a fim de garantir os fatores adequados (HAGEDOORN, CLOODT, 2003) ou o SPSS (Statistical Package for the Social Sciences) (LIN, CHEN, 2005), que é um software de Data Mining, Text Mining e estatística. Tem-se ainda o uso da PMEX (Performance Measurement Evaluation Matrix), que é uma matriz que relaciona resultados para análise estatística (MALLICK, SCHROEDER, 2005).

Dois artigos atribuem pesos a cada critério e, por meio da multiplicação pela medida na escala, chega-se a um índice final (COOPER, EDGETT, KLEINSCHMIDT, 2001; 
PILLAI, JOSHI, RAO, 2002), em que um deles sugere indicadores dicotômicos e que somatórios de cada alternativa sejam feitos para integrar (COOPER, EDGETT, KLEINSCHMIDT, 2001).

Outros quatro artigos se baseiam nas perspectivas do BSC (Balanced Scorecard) para integrar seus critérios (BREMSER, BARSKY, 2004; GARCÍA-VALDERRAMA, MULERO-MENDIGORRI, REVUELTA-BORDOY, 2008; ELMQUIST, LE MASSON, 2009; WANG, LIN, HUANG, 2010). Para esses autores os objetivos das quatro perspectivas são conectados por relações de causa e efeito (KAPLAN, NORTON, 1992; 2001; 2004).

Há um trabalho selecionado que utiliza do processo ANP (Analytic Network Process) (CHEN, HUANG, CHENG, 2009), o qual se trata de uma extensão do AHP (Analytic Hierarchy Process) e permite conectar cada critério a outro a partir de relações de influência (Sandoval, 2004). Além disso, a Teoria da Utilidade esperada entre os riscos adversos e agentes econômicos (LEE, 1971), com aplicação de probabilidade, é abordada em um caso para formular efeitos esperados nas análises de trade-offs entre os diversos critérios (CALANTONE, CHAN, CUI, 2006). E, por fim, um artigo adota uma perspectiva sistêmica do R\&D, entendendo seus inputs e outputs, integrando objetivos, dimensões, métricas e processo de medição (CHIESA, FRATTINI, LAZZAROTTI, 2009).

Os artigos concordam que, para melhorar a qualidade da informação gerada pelos indicadores, estes devem estar integrados, ou seja, que essa é prerrogativa para o diagnóstico sistêmico e holístico da situação atual e para a proposição de ações de aperfeiçoamento do contexto em sua forma global (LACERDA, ENSSLIN, ENSSLIN, 2011). Dessa forma, conclui-se que existe, na amostra de artigos, o reconhecimento da importância da integração das escalas, porém a lacuna observada se refere à maneira pela qual as constantes de integração são construídas.

\subsubsection{Gestão}

Para realizar o diagnóstico da situação e gerar ações de aperfeiçoamento, surge a última lente da revisão sistêmica utilizada para analisar os artigos do Portfólio. Para isso, classificam-se os 25 artigos do Portfólio, conforme a Figura 24, em artigos que não realizam gestão; artigos que utilizam análises qualitativas; e artigos que analisam, qualitativa e quantitativamente, os aspectos para se fazer a gestão. 
Figura 24 - Processos de Gestão presentes nos artigos do Portfólio

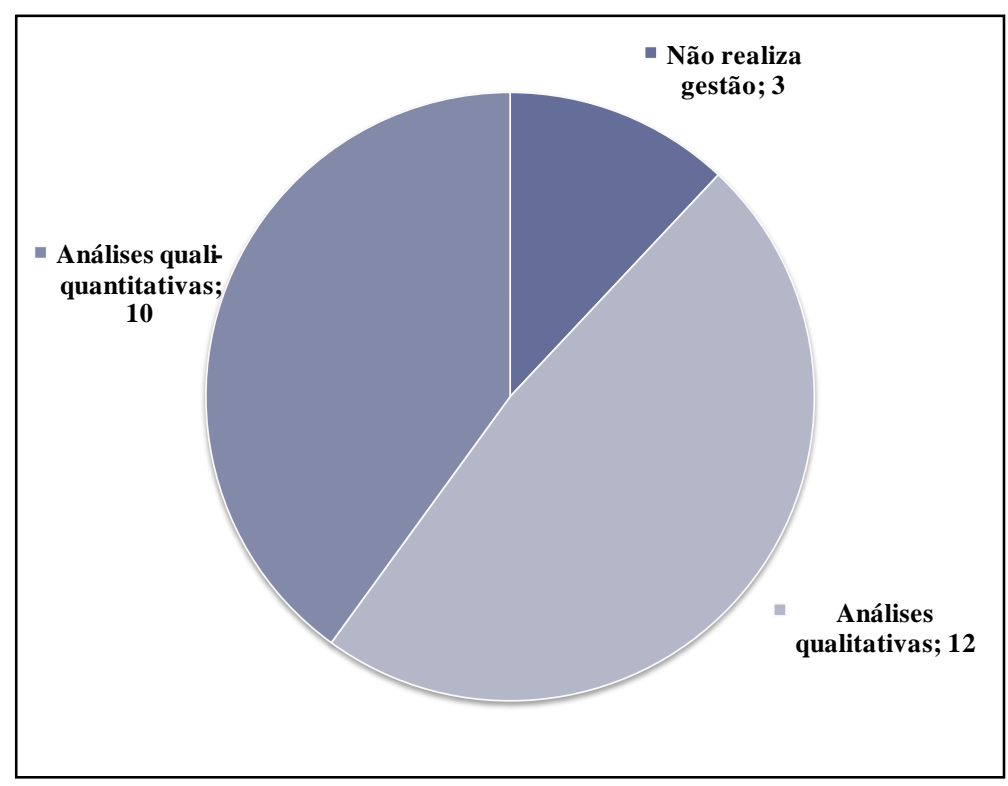

Fonte: Autoria própria (2011)

Há três artigos que não realizam ou não comentam sobre o processo de gestão (VON ZEDTWITZ, GASSMANN, BOUTELLIER, 2004; SANTIAGO, BIFANO, 2005; VUOLLE, LÖNNQVIST, VAN DER MEER, 2009).

Dentre os 22 artigos que realizam a gestão, doze utilizam um processo de análise qualitativa para diagnosticar a situação atual, em que os aspectos são avaliados e posicionam o objeto de maneira descritiva (MIKKOLA, 2001; VERMA, SINHA, 2002; HAGEDOORN, CLOODT, 2003; CORMICAN, O’SULLIVAN, 2004; GARCÍA-VALDERRAMA, MULERO-MENDIGORRI, 2005; LIN, CHEN, 2005; MALLICK, SCHROEDER, 2005; ADAMS, BESSANT, PHELPS, 2006; CHIESA, FRATTINI, LAZZAROTTI, 2009; ELMQUIST, LE MASSON, 2009; SCHMIDT, SARANGEE, MONTOYA, 2009; CEDERGREN, WALL, NORSTRM, 2010; WANG, LIN, HUANG, 2010). Como exemplos de instrumentos utilizados para a análise, são mostradas a matriz SWOT (Strengths, Weaknesses, Opportunities, Threats) (MIKKOLA, 2001; CORMICAN, O’SULLIVAN, 2004) e a análise por processo (ADAMS, BESSANT, PHELPS, 2006). As propostas de melhora de desempenho são realizadas com base em tais ferramentas, buscando melhorar determinados critérios qualitativos.

Os outros dez trabalhos utilizam análise quali-quantitativa dos aspectos para entender a situação atual, mensurando a lacuna entre a meta estabelecida e a situação atual (COOPER, EDGETT, KLEINSCHMIDT, 2001; PILLAI, JOSHI, RAO, 2002; HART et al, 2003; BREMSER, BARSKY, 2004; GARCÍA-VALDERRAMA, MULERO-MENDIGORRI, 
2005; CALANTONE, CHAN, CUI, 2006; EILAT, GOLANY, SHTUB, 2008; GARCÍAVALDERRAMA, MULERO-MENDIGORRI, REVUELTA-BORDOY, 2008; CHEN, HUANG, CHENG, 2009; PANIZZOLO, BIAZZO, GARENGO, 2010). Ferramentas desse grupo são, por exemplo, o índice integrado (PILLAI, JOSHI, RAO, 2002) e outros modos de apresentação gráfica (COOPER, EDGETT, KLEINSCHMIDT, 2001). O processo de melhora de desempenho desse grupo deriva dos intervalos de desempenho entre as metas estabelecidas e a situação atual, em que se propõe que ações sejam executadas para minimizar ou eliminar o intervalo entre esses dois pontos em um dado critério.

Nesta seção, observa-se que os modelos de Avaliação de Desempenho buscam a gestão do processo de $\mathrm{P} \& \mathrm{D}$, porém disponibilizam ao decisor ferramentas que podem ser aperfeiçoadas. Os autores do presente trabalho compartilham do conceito que, para esse aperfeiçoamento tornar a gestão efetiva, primeiramente, a construção de uma modelo de avaliação deve partir de uma abordagem construtivista e disponibilizar instrumentos cognitivos que propiciem a construção do conhecimento no decisor. Tal conhecimento deve, então, ser aperfeiçoado com a utilização de instrumentos quantitativos que forneçam precisão à Avaliação de Desempenho estratégico, buscando, dessa forma, ordenar e priorizar as ações de maior impacto (LACERDA, ENSSLIN, ENSSLIN, 2011).

\subsection{Oportunidades e pergunta de pesquisa}

A análise sistêmica do Portfólio permitiu o entendimento de que o conteúdo científico acerca de Avaliação de Desempenho na gestão do Processo de P\&D se vale de diversos métodos, processos e abordagens, com pontos fortes e com oportunidade de desenvolvimento de pesquisas, relacionadas com as seis lentes descritas no presente artigo.

Três lacunas foram identificadas como oportunidades para futuras pesquisas:

- A primeira delas se refere ao fato de nenhum modelo disponibilizar processo que lide com os limites de conhecimento do gestor (lente 3 ).

- Ao que se refere ao atendimento do reconhecimento da ordinalidade/cardinalidade, não há escala que expresse de maneira transparente a sua função de valor, ou seja, a diferença de atratividade entre todos os níveis apresentados (lente 4).

- Por último, há deficiência na descrição dos processos de integração dessas escalas para gestão efetiva do contexto (lentes 5 e 6 ).

Logo, a pergunta que emerge é: Como lidar com a limitação de conhecimento do decisor para identificar aspectos relevantes e definir escalas que associem valores aos 
diferentes níveis de desempenho nestes aspectos, de maneira integrada, a fim de diagnosticar o contexto e viabilizar o seu aperfeiçoamento? Ou seja, transmite-se como inspiração para a continuidade dos trabalhos o objetivo de desenvolver um processo de identificação e mensuração dos aspectos que trate a informação de maneira a entender seu significado de valor, de forma integrada entre todos os diferentes critérios e níveis hierárquicos para possibilitar a gestão.

\section{Considerações finais}

O presente trabalho se torna digno de ter sua importância reconhecida visto que visa construir conhecimento e possibilitar a expansão da ciência acerca de Avaliação de Desempenho no processo de gestão de Pesquisa e Desenvolvimento (P\&D), área considerada crítica para a sustentabilidade dos negócios das organizações (ADAMS, BESSANT, PHELPS, 2006).

Os autores compartilham a opinião de que inovação, quando entendida como a transformação de uma ideia em um novo produto, processo ou método (ADAMS, BESSANT, PHELPS, 2006) é uma questão complexa para as empresas contemporâneas (GRIFFIN e PAGE, 1993; FRENKEL, MAITAL, GRUPP, 2000) e que essa é a principal função do setor de Pesquisa e Desenvolvimento. Sabe-se que é um desafio realizar a gestão desse processo, do qual depende a capacidade de inovar da organização (CORDERO, 1990), sob o ponto de vista da avaliação do seu desempenho. Além do mais, reconhece-se que a literatura a respeito do tema é vasta e contempla variadas ontológicas e epistemológicas posições frente a esse contexto considerado complexo e multidimensional (WOLFE, 1994), o que torna difícil a identificação e revisão do conhecimento científico existente na área.

Portanto, desde o preâmbulo deste trabalho, objetivou-se analisar os artigos mais relevantes da literatura em gestão de $\mathrm{P} \& \mathrm{D}$ analisados sob a perspectiva da Avaliação de Desempenho para então ser capaz de orientar futuras pesquisas sobre o tema. Para isso, empregou-se um processo estruturado para seleção do Portfólio de 25 artigos e análises qualiquantitativas que comprovaram a estabilidade da amostra - bibliometria. Essa análise ainda permitiu encontrar os periódicos e trabalhos mais importantes dentro do Portfólio dos 25 artigos e evidenciá-los a fim de torná-los uma referência e evidenciar características da publicação dessa área de conhecimento. A partir disso, com a análise sistêmica, todos os artigos do Portfólio foram revisados sob as seis lentes que compõem a estrutura de valor 
proposta pelos autores, onde se julga que o processo de avaliar o desempenho deve, em qualquer contexto:

- Construir entendimento do contexto a ser avaliado.

- Disseminar o entendimento do que é importante.

- Alinhar as atividades Táticas e Operacionais aos Objetivos Estratégicos.

- Dar credibilidade e coerência às decisões.

- Ter mais qualidade no processo decisório.

- Dar fundamentação e transparência às decisões.

- Ter processo de aperfeiçoamento no monitoramento.

Por fim, a revisão sistêmica possibilitou construir conhecimento nos pesquisadores e, então, identificar lacunas passíveis de se tornarem futuras pesquisas a respeito de Avaliação de Desempenho no processo de gestão $\mathrm{P} \& \mathrm{D}$, cumprindo o proposto pelo trabalho ao sugerir oportunidades e objetivos de trabalho para futuras pesquisas à comunidade científica. Além disso, constata-se que se tem em mãos um poderoso processo, a revisão sistêmica da literatura, que pode ser empregado a qualquer momento em qualquer área de estudo, auxiliando os pesquisadores na busca por essa tão valiosa e nobre causa que é o conhecimento.

\section{Abstract}

This paper aims, from the researcher's previous knowledge about the Research and Development (R\&D) management, expand it to levels that enable to form a bibliographic portfolio on this topic, to clarify the most important articles, authors and journals and, additionally, to identify gaps that may become future research on this area. In order to this, it is carried out a systemic literature review through a structured process, which runs through four steps: i) relevant articles portfolio selection; ii) portfolio bibliometrics analysis; iii) systemic analysis; iv) research question definition and goal of future research. This process allows the researcher to build knowledge on the subject and being able to instigate new works. The importance of this is founded on the framework left to future research about R\&D and in the systemic review process legitimation as a knowledge generator.

Key-words: Performance Evaluation. R\&D Management. Systemic Review.

\section{Referências}

ABERNETHY, M. A.; LILLIS, A. M. The impact of manufacturing flexibility on management control system design. Accounting, Organizations and Society, v. 20, n. 4, p. 241-258, 1995.

ADAMS, R.; BESSANT, J.; PHELPS, R. Innovation management measurement: A review. International Journal of Management Reviews, v. 8, n. 1, p. 21-47, 2006. 
AFONSO, M. H. F.; SOUZA, J. V.; ENSSLIN, S. R.; ENSSLIN, L. Como construir conhecimento sobre o tema de pesquisa? Aplicação do processo Proknow-C na busca de literatura sobre avaliação do desenvolvimento sustentável. Revista de Gestão Social e Ambiental, v. 5, p. 47-62, 2012.

AZEVEDO, R. C.; ENSSLIN, L.; LACERDA, R. T. O.; FRANÇA, L. A.; GONZALEZ, C. J. I.; JUNGLES, A. E.; ENSSLIN, S. R. Avaliação de Desempenho do processo de orçamento: estudo de caso em uma obra de construção civil. Ambiente Construído, v.11, n.1, p.85-104. 2011.

cross ref

BAINES, A.; LANGFIELD-SMITH, K. Antecedents to management accounting change: a structural equation approach. Accounting, Organizations and Society, v. 28, n. 7-8, p. 675-698, 2003.

BALDWIN, J. M. Dictionary of Philosophy and Psychology: Encyclopædia Britannica, 2011.

BANA E COSTA, C. A.; ENSSLIN, L.; CORRÊA, É. C.; VANSNICK, J-C. Decision Support Systems in action: Integrated application in a multicriteria decision aid process. European Journal of Operational Research, v. 113, n. 2, p. 315-335, 1999.

BANKER, R. D.; POTTER, G.; SCHROEDER, R. G. Reporting manufacturing performance measures to workers: An empirical study. Journal of Management Accounting Research, v. 5, p. 33-55, 1993.

BARZILAI, J. A New Methodology for Dealing with Conflicting Engineering Design Criteria. Proceeding of the 18th Annual Meeting of the American Society for Engineering Management, p. 73-79, 1997.

BAUMOL, W. J.; WOLFF, E. N. Feedback from productivity growth to R\&D. The Scandinavian Journal of Economics, v. 2, n. 147-157, 1983.

BEAMON, B. M. Measuring supply chain performance. International Journal of Operations \& Production Management, v. 19, n. 3, p. 275-292, 1999.

cross ref

BORTOLUZZI, S. C.; ENSSLIN, S. R.; ENSSLIN, L.; VALMORBIDA, S. M. I. A Avaliação de Desempenho em redes de pequenas e médias empresas: estado da arte para as delimitações postas pelo pesquisador. Revista Eletrônica de Estratégia \& Negócios, v. 4, n. 2, p. 202-222, 2011.

BREMSER, W. G.; BARSKY, N. P. Utilizing the balanced scorecard for R\&D performance measurement. R\&D Management, v. 34, n. 3, p. 229-238, 2004.

cross ref

CALANTONE, R. J.; CHAN, K.; CUI, A. S. Decomposing product innovativeness and its effects on new product success. Journal of Product Innovation Management, v. 23, n. Compendex, p. 408-421, 2006.

CEDERGREN, S.; WALL, A.; NORSTRM, C. Evaluation of performance in a product development context. Business Horizons, v. 53, n. 4, p. 359-69, 2010.

CHEN, M.-Y.; HUANG, M.-J.; CHENG, Y.-C. Measuring knowledge management performance using a competitive perspective: An empirical study. Expert Systems with Applications, v. 36, n. Compendex, p. 8449-8459, 2009.

CHIESA, V.; FRATTINI, F.; LAZZAROTTI, V.; MANZINI, R. Performance measurement in R\&D: exploring the interplay between measurement objectives, dimensions of performance and contextual factors. R\&D Management, v. 39, n. 5, p. 488-518, 2009.

CHISNALL, P. Analysis and Measurement. McGraw-Hill: Marketing Research, 1973.

CHURCILL; PETER, J. P. Marketing - criando valor para os clientes. Editora Saraiva, 2000. 
COOPER, R.; EDGETT, S.; KLEINSCHMIDT, E. Portfolio management for new product development: Results of an industry practices study. R\&D Management, v. 31, n. 4, p. 361-380, 2001.

\section{cross ref}

CORDERO, R. The measurement of innovation performance in the firm: an overview. Research Policy, v. 19, p. 185-192, 1990.

cross ref

CORMICAN, K.; O'SULLIVAN, D. Auditing best practice for effective product innovation management. Technovation, v. 24, n. 10, p. 819-829, 2004.

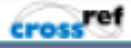

DE MORARES, L.; GARCIA, R.; ENSSLIN, L.; DA CONCEIÇÃO, M.; DE CARVALHO, S. The multicriteria analysis for construction of bench markers to support the Clinical Engineering in the Healthcare Technology Management. European Journal of Operational Research, v. 200, p. 607-615, 2010.

\section{cross ref}

DENYER, D.; NEELY, A. Introduction to special issue: Innovation and productivity performance in the UK. International Journal of Management Reviews, v. 5, n. 3-4, p. 131-135, 2004.

DONNELLY, G. A. P\&L for R\&D. CFO Magazine, v. 16, p. 44-50, 2000.

DOSI, G. Sources, procedures and microeconomic effects of innovation. Journal of Economic Literature, v. 1, p. 1120-1171, 1988.

EARTO. 2010. Disponível em: < www.earto.org >. Acesso em: 10/30/2010.

ECCLES, R. G. The performance measurement manifesto. Harvard Business Review, p. 131-137, 1991.

EILAT, H.; GOLANY, B.; SHTUB, A. R\&D project evaluation: An integrated DEA and balanced scorecard approach. Omega-International Journal of Management Science, v. 36, n. 5, p. 895-912, 2008.

ELMQUIST, M.; LE MASSON, P. The value of a 'failed' R\&D project: an emerging evaluation framework for building innovative capabilities. R\&D Management, v. 39, n. 2, p. 136-152, 2009.

ENSSLIN, L.; DE CAMPOS, M. L. A prática do aprendizado organizacional. Revista Gestão Industrial, v. 2 , p. 58-68, 2006.

ENSSLIN, L.; DUTRA, A.; ENSSLIN, S. R. MCDA: a constructivist approach to the management of human resources at a governmental agency. International Transactions in Operational Research, v. 7, p. 79-100, 2000.

cross ref

ENSSLIN, L.; ENSSLIN, S. R.; DUTRA, A.; PETRI, S. M. Identificando e analisando problemas de performance: o uso da Avaliação de Desempenho (Feedback, Coaching e Counseling) para melhorar a produtividade dos empregados. Florianópolis: UFSC 2007.

ENSSLIN, L.; ENSSLIN, S. R.; LACERDA, R. T. O.; TASCA, J. E. ProKnow-C, Knowledge Development Process- Constructivist. Processo técnico com patente de registro pendente junto ao INPI. Brasil, 2010a.

ENSSLIN, L.; GIFFHORN, E.; ENSSLIN, S. R.; PETRI, S. M.; VIANNA, W. B. Avaliação do Desempenho de Empresas Terceirizadas com o uso da Metodologia Multicritério em Apoio à Decisão - Construtivista. Pesquisa Operacional (Impresso), v. 30, n. 125-152, Janeiro a Abril de 2010b.

ENSSLIN, L; ENSSLIN, S.R. Material didático apresentado na Disciplina: Avaliação de Desempenho do Programa de Pós-graduação em Engenharia de Produção da Universidade Federal de Santa Catarina. Florianópolis: UFSC, 2010. 
ENSSLIN, S. R.; CARVALHO, F. N. de; GALLON, A. V.; ENSSLIN, L. Uma metodologia multicritério (MCDA-C) para apoiar o gerenciamento do capital intelectual organizacional. RAM, Rev. Adm. Mackenzie (Online), v.9, n.7, p.136-162, 2008.

ENSSLIN, L; ENSSLIN, S.R. Material didático apresentado na Disciplina: Avaliação de Desempenho do Programa de Pós-graduação em Engenharia de Produção da Universidade Federal de Santa Catarina. Florianópolis: UFSC, 2007.

ENSSLIN, S. R.; CARVALHO, F. N. De. Voluntary Disclousure od Intellectual Capital in the Brazilian Context: an Investigation Informed by the International Context. International Journal Accounting, Auditing and Performance Evaluation, v. 4, p. 478-500, 2007.

crossef

ENSSLIN, L.; MONTIBELLER, G. N.; NORONHA, S. M. Apoio à Decisão - Metodologia para Estruturação de Problemas e Avaliação Multicritério de Alternativas. Florianópolis: Insular, 2001. FASTS. 2010. Disponível em: < www.fasts.org >. Acesso em: 10/30/2010.

FRENKEL, A.; MAITAL, S.; GRUPP, H. Measuring dynamic technical change: a technometric approach. International Journal of Technology Management, v. 20, p. 429-441, 2000.

cross ref

FULLERTON, R. R.; MCWATTERS, C. S. The role of performance measures and incentive systems in relation to the degree of JIT implementation. Accounting, Organizations and Society, v. 27, n. 8, p. 711-735, 2002.

GARCÍA-VALDERRAMA, T.; MULERO-MENDIGORRI, E. Content validation of a measure of R\&D effectiveness. R\&D Management, v. 35, n. 3, p. 311-331, 2005.

crossef

GARCÍA-VALDERRAMA, T.; MULERO-MENDIGORRI, E.; REVUELTA-BORDOY, D. A balanced scorecard framework for R\&D. European Journal of Innovation Management, v. 11, n. 2, p. 241-281, 2008.

cross ref

GIFFHORN, E.; ENSSLIN, L.; ENSSLIN, S. R.; VIANNA, W. B. Aperfeiçoamento da Gestão Organizacional por meio da Abordagem Multicritério de Apoio à Decisão. Revista Gestão Industrial, v. 5, n. 4, p. 183-204, 2009.

cross $r e f$

GRIFFIN, A.; PAGE, A. L. An interim report on measuring product development success and failure. Journal of Product Innovation Management, v. 10, n. 4, p. 291-308, 1993.

HAGEDOORN, J.; CLOODT, M. Measuring innovative performance: is there an advantage in using multiple indicators? Research Policy, v. 32, n. 8, p. 1365-1379, 2003.

HALL, R. W.; JOHNSON, H. T.; TURNEY, P. B. B. Measuring up: Charting pathways to manufacturing excellence. Homewood, IL: 1990.

HART, S.; HULTINK, E. J.; TZOKAS, N.; COMMANDEUR, H. R. Industrial companies' evaluation criteria in new product development gates. Journal of Product Innovation Management, v. 20, n. 1, p. 22-36, 2003.

cross ${ }^{\text {ref }}$

HAUSER, J. R.; ZETTELMEYER, F. Metrics to evaluate RD\&E. Research-Technology Management, 1997.

HENRI, J.-F. Organizational culture and performance measurement systems. Accounting, Organizations and Society, v. 31, n. 1, p. 77-103, 2006. 
HULTINK, E. J.; ROBBEN, H. S. J. Measuring New Product Success: The Difference that Time Perspective Makes. Journal of Product Innovation Management, v. 12, n. 5, p. 392-405, 1995.

IEEE Transactions on Engineering Management. Browse - Journals - IEEE Transactions on Engineering Management, 2011. Disponível em:

$<$ http://ieeexplore.ieee.org/xpl/RecentIssue.jsp?reload=true\&punumber=17 >.

International Monetary Fund. Global Financial Stability Report, 13/04/2011 2011. Disponível em: < http://www.imf.org >.

ITO, K.; PUCIK, V. R\&D spending, domestic competition, and export performance of Japanese manufacturing firms. Strategic Management Journal, v. 1, p. 61-75, 1993.

\section{cross ref}

Journal of Product Innovation Management. Journal Menu - Aims and Scope, 2011. Disponível em: < http://www.wiley.com/bw/journal.asp?ref=0737-6782 >.

KAPLAN, R. S. Measuring Manufacturing Performance: A New Challenge for Managerial. The Accounting Review, v. 58, p. 686-705, 1983.

KAPLAN, R. S.; NORTON, D. P. The Balanced Scorecard measures that drive performance. Harvard Business Review, 1992.

KAPLAN, R. S.; NORTON, D. P. Transforming the Balanced Scorecard from Performance Measurement to Strategic Management: Part I. Accounting Horizons, v. 15, 2001.

KAPLAN, R. S.; NORTON, D. P. Strategy maps: converting intangible assets into tangible outcomes BostonMA: Harvard Business School Publishing Corporation, 2004.

KEENEY, R. L. Value Focused-Thinking: A Path to Creative Decision-making. Cambridge: Harvard University Press, 1992.

LACERDA, R. T. O.; ENSSLIN, L.; ENSSLIN, S. R. A performance measurement view of IT project management. International Journal of Productivity and Performance Management, v. 60, n. 2, p. 132-151, 2011.

cross ref

LACERDA, R. T. O., ENSSLIN, L. ; ENSSLIN, S. R. Uma Análise Bibliométrica da Literatura Sobre Estratégia e Avaliação de Desempenho . Gestão \& Produção, v.19, n.1. 2012.

\section{cross ref}

LEE, J.; SHIN, E. Moderating effects of R\&D on corporate growth in U.S. and Japanese hi-tech industries: an empirical study. The Journal of High Technology Management Research, v. 2, p. 179-191, 1995.

\section{cross ref}

LEE, W. Decision theory and human behavior. Oxford, England: John Wiley \& Sons, 1971.

LIN, B. W.; CHEN, J. S. Corporate technology portfolios and R\&D performance measures: A study of technology intensive firms. R\&D Management, v. 35, n. 2, p. 157-170, 2005.

\section{cross ref}

LONG, W. F.; RAVENSCRAFT, D. J. LBO's debt and R\&D intensity. Strategic Management Journal, v. 1, p. $119-135,1993$.

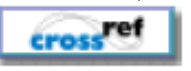


MALLICK, D. N.; SCHROEDER, R. G. An integrated framework for measuring product development performance in high technology industries. Production and Operations Management, v. 14, n. 2, p. 142-158, 2005.

\section{cross}

MARAFON, A., ENSSLIN, L., LACERDA, R. T. O., ENSSLIN, S. R. The Implications Of R \& DManagement For Organisational Effectiveness: A Literature Review. IEEE International Technology ManagementConference. Dallas, TX, USA: (C2012 IEEE. June 25-27, p.202-211. 2012.

MCT. Indicadores - Dispêndio nacional em pesquisa e desenvolvimento (P\&D) em valores correntes, em relação ao total de P\&D e ao produto interno bruto (PIB), por setor institucional, Brasilia, 2010. Disponível em: < www.mct.gov.br >.

MIKKOLA, J. H. Portfolio management of R \& D projects: Implications for innovation management. Technovation, v. 21, n. 7, p. 423-435, 2001.

cross ref

MORBEY, G. K.; REITHNER, R. M. How R\&D affects sales growth, productivity and profitability. Research Technology Management, v. 3, p. 11-14, 1990.

MOST. S\&T Statistics Data Book, Beijing, 2010. Disponível em: < http://www.most.gov.cn >.

NANNI, A. J.; DIXON, J. R.; VOLLMANN, T. E. Integrated performance measurement: Management accounting to support the new manufacturing realities. Journal of Management Accounting Research, v. 4, p. $1-19,1992$.

OECD. Statistics - Country statistical profiles: Key tables from OECD. OECD - Organisation for Economic Co-operation and Development. 2008

OECD; EUROSTAT. Oslo Manual: Guidelines For Collecting And Interpreting Innovation Data. 3. Paris: OECD - Organisation for Economic Co-operation and Development, 2005.

OJANEN, V.; VUOLA, O. Coping with the multiple dimensions of R\&D performance analysis. International Journal of Technology Management, v. 33, p. 279-290, 2006.

\section{cross ref}

PANIZZOLO, R.; BIAZZO, S.; GARENGO, P. New product development assessment: Towards a normativecontingent audit. Benchmarking, v. 17, n. 2, p. 173-194, 2010.

\section{cross ref}

PERERA, S.; HARRISON, G.; POOLE, M. Customer-focused manufacturing strategy and the use of operations-based non-financial performance measures: A research note. Accounting, Organizations and Society, v. 22, n. 6, p. 557-572, 1997.

PILLAI, A. S.; JOSHI, A.; RAO, K. S. Performance measurement of R and D projects in a multi-project, concurrent engineering environment. International Journal of Project Management, v. 20, n. 2, p. 165-177, 2002 .

\section{cross ref}

PRITCHARD, A. Statistical bibliography or bibliometricas. Journal of Documentation, v. 25, p. 348-349, 1969.

R\&D Management. Journal Menu - Aims and Scope, 2011. Disponível em: < http://www.blackwellpublishing.com/journal.asp?ref=0033-6807 >.

Research Policy. Browse Journals - Research Policy, 2011. Disponível em: < http://www.elsevier.com/wps/find/journaldescription.cws_home/505598/description\#description >. 
ROSA, F. S.; ENSSLIN, S. R.; ENSSLIN, L. Evidenciação Ambiental: Processo Estruturado de Revisão de Literatura sobre Avaliação de Desempenho da Evidenciação Ambiental. Sociedade, Contabilidade e Gestão, v. 4, n. 2, p. 24-37, 2009.

ROY, B. Decision science or decision-aid science. European Journal of Operational Research, v. 66, p. 184203, 1993.

cross ref

ROY, B. On operational research and decision aid. European Journal of Operational Research, v. 73, p. 2326, 1994.

crossef

ROY, B. Paradigms and Challenges, Multiple Criteria Decision Analysis - State of the Art Survey.

International Series in Operations Research \& Management Science, 2005.

ROY, B.; VANDERPOOTEN, D. The European School of MCDA: A Historical Review. LAMSADE Université Paris-Dauphin. Paris. 1995

ROY, B.; VANDERPOOTEN, D. The european school of MCDA: emergence, basic features and current works. Journal of Multi-Criteria Decision Analysis, 1996.

cross ${ }^{\text {ref }}$

SAES, S. G. Estudo bibliométrico das publicações em economia da saúde, no Brasil 1989-1998. Programa de Pós-Graduação em Administração, Serviços de Saúde, Faculdade de Saúde Pública da Universidade de São Paulo, 2000.

SANDOVAL, C. Comparing AHP and ANP shiftworks models: Hierarchy simplicity vs Network connectivity. Fulcrum Engineering, 2004.

SANTIAGO, L. P.; BIFANO, T. G. Management of R\&D projects under uncertainty: A multidimensional approach to managerial flexibility. IEEE Transactions on Engineering Management, v. 52, n. 2, p. 269-280, 2005.

cross ref

SCHMIDT, J. B.; SARANGEE, K. R.; MONTOYA, M. M. Exploring new product development project review practices. Journal of Product Innovation Management, v. 26, n. 5, p. 520-535, 2009.

cross ref

SKINNER, W. The productivity paradox. Management Review, v. 75, n. 9, p. 41-45, 1986.

SPINAK, E. Indicadores cienciometricos. Ci. Inf. [online], v. 27, 1998.

TASCA, J. E.; ENSSLIN, L.; ENSSLIN, S. R.; M., A. M. B. An approach for selecting a theoretical framework for the evaluation of training programs. Journal of European Industrial Training, v. 34, p. 631-655, 2010.

crossef

TRANFIELD, D. R.; DENYER, D.; SMART, P. Towards a Methodology for Developing EvidenceInformed Management Knowledge by Means of Systematic Review. SSRN eLibrary, 2003.

VERMA, D.; SINHA, K. K. Toward a theory of project interdependencies in high tech R \& D environments. Journal of Operations Management, v. 20, n. 5, p. 451-468, 2002.

cross ref

VINCKE, P. L'Aide Multicritère À La Dècision. Bruxelas: Éditions de l'Université de Bruxelles, 1989. 
VON ZEDTWITZ, M.; GASSMANN, O.; BOUTELLIER, R. Organizing global R\&D: Challenges and dilemmas. Journal of International Management, v. 10, n. 1 SPEC ISS., p. 21-49, 2004.

VUOLLE, M.; LÖNNQVIST, A.; VAN DER MEER, J. Measuring the intangible aspects of an R\&D project. Measuring Business Excellence, v. 13, n. 2, p. 25-33, 2009.

\section{cross ${ }^{\text {ref }}$}

WANG, C. H.; CHIN, Y. C.; TZENG, G. H. Mining the R\&D innovation performance processes for high-tech firms based on rough set theory. Technovation, v. 30, n. 7-8, p. 447-458, 2010.

WANG, J.; LIN, W.; HUANG, Y. H. A performance-oriented risk management framework for innovative R\&D projects. Technovation, v. 30, n. 11-12, p. 601-611, 2010.

cross ref

WOLFE, R. A. Organizational innovation: review, critique and suggested research directions. Journal of Management Studies, v. 31, p. 405-431, 1994.

\section{cross ref}

\section{Dados dos autores:}

Nome completo: Alysson Diego Marafon

Filiação institucional: Universidade Federal de Santa Catarina

Departamento: Engenharia de Produção

Função ou cargo ocupado: Mestrando

Endereço completo para correspondência (bairro, cidade, estado, país e CEP): Rua Ana Maria Nunes, n.110 - Residencial Recanto Verde - Apto. 201B - Bairro Córrego Grande - CEP 88.037-020 - Florianópolis/SC

Telefones para contato: (47) 9984-0790

e-mail: alyssonmarafon@gmail.com

\section{Nome completo: Leonardo Ensslin}

Filiação institucional: Universidade Federal de Santa Catarina

Departamento: Engenharia de Produção

Função ou cargo ocupado: Professor Titular

Endereço completo para correspondência (bairro, cidade, estado, país e CEP): Universidade

Federal de Santa Catarina - Departamento de Engenharia de Produção - EPS - Campus

Universitário - Trindade - Cx Postal 476 - CEP 88.010-970 - Florianópolis/SC

Telefones para contato: (48) 9983-0386

e-mail: leonardoensslin@gmail.com 
Filiação institucional: Universidade Federal de Santa Catarina

Departamento: Contabilidade

Função ou cargo ocupado: Professora Associada

Endereço completo para correspondência (bairro, cidade, estado, país e CEP): Universidade Federal de Santa Catarina - Departamento da Contabilidade - Campus Universitário Trindade - Cx Postal 476 - CEP 88.010-970 - Florianópolis/SC

Telefones para contato: (48) 3209-1916

e-mail:sensslin@gmail.com

Nome completo: Rogério Tadeu Lacerda

Filiação institucional: Universidade Federal de Santa Catarina

Departamento: Engenharia de Produção

Função ou cargo ocupado: Doutorando

Endereço completo para correspondência (bairro, cidade, estado, país e CEP): Universidade

Federal de Santa Catarina - Departamento de Engenharia de Produção - EPS - Campus Universitário - Trindade - Cx Postal 476 - CEP 88.010-970 - Florianópolis/SC

Telefones para contato: (47) 9984-0790

e-mail: rogerlacerda@gmail.com

Recebido em: $25 / 05 / 2011$

Aceito em: 19/07/2012 